\title{
Functionally Active Fc Mutant Antibodies Recognizing Cancer Antigens Generated Rapidly at High Yields
}

Kristina M. Ilievar,2, Judit Fazekas-Singer,3,4 Daniela Y. Achkova ${ }^{5}$, Thhomir S. Dodev ${ }^{1,6}$, Silvia Mele', Silvia Crescioli ${ }^{1}$, Heather J. Bax', Anthony Cheung ${ }^{1,2}$, Panagiotis Karagiannis ${ }^{1,7}$, Isabel Correa', Mariangela Figini ${ }^{8}$, Rebecca Marlow ${ }^{2}$, Debra H. Josephs ${ }^{1,5}$, Andrew J. Beavil ${ }^{6}$, John Maher ${ }^{5,9,10}$, James F. Spicer ${ }^{5}$, Erika Jensen-Jarolim ${ }^{3,4}$, Andrew N. Tutt ${ }^{2}$ and Sophia N. Karagiannis ${ }^{1,2 *}$

OPEN ACCESS

Edited by:

Jose A. Garcia-Sanz,

Consejo Superior de Investigaciones

Cientificas (CSIC), Spain

Reviewed by:

Ann White,

UCB Pharma, United Kingdom

Rajko Reljic,

St George's, University of London,

United Kingdom

Stephen Andrew Beers,

University of Southampton,

United Kingdom

*Correspondence:

Sophia N. Karagiannis

sophia.karagiannis@kcl.ac.uk

Specialty section:

This article was submitted to Cancer Immunity and Immunotherapy,

a section of the journal

Frontiers in Immunology

Received: 29 June 2017 Accepted: 24 August 2017 Published: 11 September 2017

Citation:

llieva KM, Fazekas-Singer J, Achkova DY, Dodev TS, Mele S, Crescioli S, Bax HJ, Cheung A, Karagiannis $P$, Correa I, Figini $M$, Marlow R, Josephs DH, Beavil AJ,

Maher J, Spicer JF,

Jensen-Jarolim E, Tutt AN and Karagiannis SN (2017) Functionally

Active FC Mutant Antibodies

Recognizing Cancer Antigens

Generated Rapidly

at High Yields.

Front. Immunol. 8:1112.

doi: 10.3389/fimmu.2017.01112
'St John's Institute of Dermatology, Division of Genetics and Molecular Medicine, King's College London, Guy's Hospital, London, United Kingdom, ${ }^{2}$ Breast Cancer Now Unit, School of Cancer Sciences, Guy's Cancer Centre, King's College London, London, United Kingdom, ${ }^{3}$ Comparative Medicine, The Interuniversity Messerli Research Institute of the University of Veterinary Medicine Vienna, University of Vienna, Vienna, Austria, ${ }^{4}$ Institute of Pathophysiology and Allergy Research, Center of Pathophysiology, Infectiology and Immunology, Medical University of Vienna, Vienna, Austria, ${ }^{5}$ School of Cancer Sciences, King's College London, Bermondsey Wing, Guy's Hospital, London, United Kingdom, ${ }^{6}$ Randall Division of Cell and Molecular Biophysics, King's College London, New Hunt's House, London, United Kingdom, ' Department of Oncology, Haematology and Stem Cell Transplantation, University Hospital of Hamburg Eppendorf, Hamburg, Germany, ${ }^{8}$ Molecular Therapies Unit, Department of Experimental Oncology and Molecular Medicine, Fondazione IRCCS Istituto Nazionale dei Tumori Milano, Milan, Italy, ${ }^{9}$ Department of Clinical Immunology and Allergy, King's College Hospital NHS Foundation Trust, London, United Kingdom, ${ }^{10}$ Department of Immunology, Eastbourne Hospital, Eastbourne, United Kingdom

Monoclonal antibodies find broad application as therapy for various types of cancer by employing multiple mechanisms of action against tumors. Manipulating the Fc-mediated functions of antibodies that engage immune effector cells, such as NK cells, represents a strategy to influence effector cell activation and to enhance antibody potency and potentially efficacy. We developed a novel approach to generate and ascertain the functional attributes of Fc mutant monoclonal antibodies. This entailed coupling single expression vector (pVitro1) antibody cloning, using polymerase incomplete primer extension (PIPE) polymerase chain reaction, together with simultaneous Fc region point mutagenesis and high yield transient expression in human mammalian cells. Employing this, we engineered wild type, low (N297Q, NQ), and high (S239D/I332E, DE) FCR-binding FC mutant monoclonal antibody panels recognizing two cancer antigens, HER2/neu and chondroitin sulfate proteoglycan 4. Antibodies were generated with universal mutagenic primers applicable to any lgG1 pVitro1 constructs, with high mutagenesis and transfection efficiency, in small culture volumes, at high yields and within 12 days from design to purified material. Antibody variants conserved their Fab-mediated recognition of target antigens and their direct anti-proliferative effects against cancer cells. Fc mutations had a significant impact on antibody interactions with Fc receptors (FcRs) on human NK cells, and consequently on the potency of NK cell activation, quantified by immune complex-mediated calcium mobilization and by antibody-dependent cellular cytotoxicity (ADCC) of tumor cells. This strategy for manipulation and testing of Fc region engagement with cognate FcRs can facilitate the design of antibodies with defined effector functions and potentially enhanced efficacy against tumor cells.

Keywords: antibodies, cancer immunotherapy, mutants, cloning, expression, ADCC, HER2, chondroitin sulfate proteoglycan 4 


\section{INTRODUCTION}

Monoclonal antibodies for cancer therapy engender a range of anti-tumor functions. These may be defined by Fab region recognition of target antigen epitopes and by engagement of the $\mathrm{Fc}$ region with cognate $\mathrm{Fc}$ receptors $(\mathrm{FcR})$ on a variety of effector cell subsets. Anti-tumor functions can include direct tumor cell killing through Fab-mediated antagonistic activity (1-6), or modulating the behavior of cytotoxic $\mathrm{T}$ cells by checkpoint blockade $(7,8)$. Furthermore, Fc-mediated effects such as complement-dependent cytotoxicity (CDC) $(6,9,10)$, antibody-dependent cellular cytotoxicity $(\operatorname{ADCC})(5,6,11,12)$ and phagocytosis (ADCP) (13) constitute important functions of a large proportion of clinically used antibodies in oncology. As many antibodies can exert multimodal anti-tumor activities influenced by both Fab- and Fc-mediated effects $(6,14)$, engineering antibodies with defined attributes and delineating their mechanisms of action is important for the generation of effective therapeutic agents.

The Fc portion of the antibody and the nature and affinity of its interactions with FcRs are critical in determining antibody serum and tissue half-life, bio-distribution (15), recruitment, and activation of immune effector cells such as NK cells and macrophages against specific target cells (16). Even though monoclonal antibodies are potent anti-cancer therapeutics, their potency in restricting disease progression may be limited by low affinity for activating FcRs, competition with endogenous serum antibodies, low half-life in tissues and interactions with the inhibitory Fcy receptor, FcyRIIB, which restricts effector cell functions $(17,18)$. On the other hand, agonistic antibodies specific for the TNFR family molecules have been reported to be significantly more efficacious if they have higher affinity for the inhibitory receptor Fc $\gamma$ RIIB and lower affinity for activating FcRs $(19,20)$. This further highlights the crucial importance of assessing the contributions of the Fc region in different antibody immunotherapy approaches for cancer and the unmet need for novel Fc-engineered antibody variants to serve the purposes of specific strategies. Protein engineering methods utilizing structural bioinformatics and computational design have identified amino acid residues that can play key roles in enhancing antibody FcR-binding and Fc-mediated functional capabilities (21). Alternatively, abrogation of antibody binding to FcRs and abolition of Fc-mediated effector functions could be a useful approach for the design of antibodies with direct agonistic or antagonistic activities where effector cell engagement may not be desirable (22-25). Developing a strategy to easily manipulate antibody Fc regions can help to dissect the mechanisms of action of anti-cancer antibodies, allowing analysis of Fab-mediated functions in the presence or absence of Fc-mediated activities. Such approaches could find a broad applicability in therapeutic antibody engineering and translation (26-28).

In vitro and in vivo potency and mechanistic evaluations of engineered antibodies and their downstream applications in cancer research are heavily dependent on the availability of sufficient quantities of high quality functional material generated from expression systems such as human embryonic kidney (HEK293), Chinese hamster ovary (CHO), and mouse myeloma
(SP2/0, NS0) cells (29-31), mostly utilizing variable regions derived from hybridoma $(32,33)$ or phage display technologies (34). Current approaches largely rely on the generation of stable expressing cell lines, and do not include efficient built-in tools for sequence engineering and mutagenesis, which may be lengthy and labor-intensive (35).

We previously reported the design and implementation of a single dual expression vector system combined with efficient insertion of any antibody variable and constant regions through polymerase incomplete primer extension (PIPE) cloning. We showed that this can facilitate antibody production by human embryonic kidney (HEK293F) cells $(36,37)$. In this study, by employing a novel cloning approach based on PIPE combined with simultaneous point mutagenesis, we generate monoclonal antibodies specific for tumor-associated antigens with modified $\mathrm{Fc}$ domains designed to alter interactions with immune effector cells. Most well established mutagenesis cloning methods require a two round PCR method or cannot be applied to large plasmids without increasing the risk of random amplification error (37-40). Our study represents an improvement of traditional PCR mutagenesis methods by offering efficient mutagenesis (requiring one round of PCR only), combined with enzyme-free cloning for the generation of large expressionready constructs (over 8,000 kb). We also designed this system to allow generation of different versions of the same antibody construct. This could find wide applicability for functional and translational studies and could be applied to any IgG1 antibody due to the universal nature of the mutagenesis approach we are employing. To our knowledge, this is the first antibody production platform that combines generation and functional validation of high yields of specific Fc mutant antibodies. With this strategy, we aim to design agents with defined effector functions in a substantially shorter timeframe, employing small culture volumes and at significantly higher yields.

\section{MATERIALS AND METHODS}

\section{Isolation of Human Immune Cells}

Peripheral blood was obtained through the UK National Health System (NHS) Blood and Transplant system from anonymous donor leukocyte cones. NK cells were isolated using RosetteSep ${ }^{\mathrm{TM}}$ Human NK Cell Enrichment Cocktail (STEMCELL ${ }^{\mathrm{TM}}$ Technologies), according to the manufacturer's instructions.

\section{Cell Culture}

All tumor cell lines were sustained at $37^{\circ} \mathrm{C}$ in a humidified atmosphere in $5 \% \mathrm{CO}_{2}$, unless otherwise specified. Cell culture medium was supplemented with $10 \%$ fetal calf serum (FCS, Thermo Fischer Scientific), unless otherwise specified. Adherent cells were detached using $0.25 \%$ Trypsin-EDTA except for cancer cell lines expressing the trypsin sensitive antigen chondroitin sulfate proteoglycan 4 (CSPG4), which were detached using $5 \mathrm{mM}$ EDTA solution in phosphate buffered saline (PBS). The cell lines BT-474 (invasive ductal carcinoma, primary site derived), SK-BR-3 (invasive ductal carcinoma, metastasis 
origin) MDA-MB-231 (invasive ductal carcinoma, metastasis origin), and Hs 578T (breast carcinoma, primary site derived) were purchased from the American Tissue Culture Collection (ATCC) and cultured in DMEM GlutaMAX ${ }^{\mathrm{TM}}$ (Thermo Fischer Scientific). The cell lines HCC1954 (invasive ductal carcinoma, primary site derived), MDA-MB-231 HTB-26 (human breast adenocarcinoma, metastasis origin), ZR-75-30 (invasive ductal carcinoma, metastasis origin) and BT-549 (invasive ductal carcinoma, lymph node metastasis origin) were purchased from ATCC and cultured in RPMI GlutaMAX ${ }^{\mathrm{TM}}$ (Thermo Fischer Scientific). MDA-MB-231-CSPG4 ${ }^{+++}$cells were generated inhouse by knocking in the coding sequence of the full-length tumor-associated antigen CSPG4 (GenBank accession number BC172576) and cells were cultured as the wild type (WT) cells. Expi293F cells (Thermo Fischer Scientific) were grown on a Stuart orbital shaker (model SSL1) (41), at $125 \mathrm{rpm}$ in $8 \% \mathrm{CO}_{2}$ in serum-free Expi293 expression medium (Thermo Fischer Scientific).

\section{Generation of Fc Mutant Antibodies}

The amino acid sequences of the trastuzumab heavy and light variable regions were obtained from the DrugBank database (www.drugbank.ca), translated in nucleotide sequences and manually codon optimized for a human expression host. Optimized sequences were synthesized using GeneArt Gene Synthesis (Thermo Fischer Scientific). The variable region fragments of trastuzumab were then cloned into pVitro1hygro-mcs vector as previously described (36). PIPE PCR was then performed using the ready cloned WT antibody pVitrol constructs as a template and mutagenic PIPE primers to generate four linear fragments of the construct with $5^{\prime}$ PIPE overhangs ("sticky ends" for PIPE cloning) and the desired point mutations (Table 1). The PCR reagents are listed in Table S1 in Supplementary Material. The cycling conditions used for execution of the mutagenic PCRs were as described before (36), but with varying extension times (Table 2), depending on the length of the fragment, optimized to favor the incomplete extension. The PCRs were performed on a ProFlex $3 \times 32$-well PCR System thermal cycler (Thermo Fischer Scientific). The amplified DNA fragments were subjected to DpnI (New England Biolabs) digestion for $2 \mathrm{~h}$ at $37^{\circ} \mathrm{C}$. Following the digestion, the four PCR products were diluted three times with deionized water, then mixed unpurified in a ratio of $1: 1: 1: 1$, incubated at room temperature for $30 \mathrm{~min}$ to overnight and between 4 and $10 \mu \mathrm{L}$ of the mixture were transformed into One Shot TOP10 chemically competent E. coli cells (Thermo Fischer Scientific), according to the manufacturer's instructions. Successful cloning was confirmed by Sanger sequencing (Source BioScience Sanger Sequencing Service, UK).

\section{Production of Monoclonal Antibodies}

Expi293F cells were transfected with the pVitro1-hygro-mcs antibody construct using the ExpiFectamine293 Transfection kit (Thermo Fischer Scientific) as per manufacturer's instructions. Transfection was carried out in Expi293 Expression Medium (Thermo Fischer Scientific). Supernatants of Expi293F cells transfected with an indicated antibody construct were harvested, spun down at $300 \times g$ for $5 \mathrm{~min}$ and then at $3,100 \times g$ for $40 \mathrm{~min}$ and filtered using a $0.45 \mu \mathrm{m}$ membrane. For comparative studies, anti-CSPG4 WT IgG1 antibody (anti-CSPG4 WT) was produced using the previously described HEK293-F method (36), as follows: starting with transient transfection and using $30 \mathrm{~mL}$ cultures in $125 \mathrm{~mL}$ shaker flasks for 2 weeks under Hygromycin B (Thermo Fischer Scientific) selection, those were subsequently scaled up to $500 \mathrm{~mL}$ in $1 \mathrm{~L}$ shaker flasks. The

\begin{tabular}{|c|c|c|c|}
\hline $\begin{array}{l}\text { Primer } \\
\text { name }\end{array}$ & Sequence $5^{\prime} \rightarrow 3^{\prime}$ & Mutation & $\begin{array}{l}\text { Amplified } \\
\text { fragment }\end{array}$ \\
\hline F-DE-1 & $\begin{array}{l}\text { CAGCACCTGAACTCCTGGGGGG } \\
\text { ACCGGACGTCTTCCTCTTCCCCC }\end{array}$ & S239D & DE F1 \\
\hline R-DE-1 & $\begin{array}{l}\text { GGGGCTGCCCTTGGCTTGGAGATG } \\
\text { GTITCTCTTCGGGGGCTGG }\end{array}$ & I332E & DE F1 \\
\hline F-DE-2 & $\begin{array}{l}\text { CCAGCCCCCGAAGAGAAAACCATC } \\
\text { TCCAAAGCCAAAGGGCAGCCCC }\end{array}$ & I332E & DE F2 \\
\hline $\begin{array}{l}\text { R-pVitro- } \\
\text { 1-Kappa }\end{array}$ & $\begin{array}{l}\text { ACCGCGGCTAGCTGGAACCC } \\
\text { AGAGCAGCAGAAACCCAATG }\end{array}$ & - & DE F2 \\
\hline $\begin{array}{l}\text { F-pVitro- } \\
\text { VL-Univ }\end{array}$ & $\begin{array}{l}\text { CATTGGGTTCTGCTGCTCTG } \\
\text { GGTTCCAGCTAGCCGCGGT }\end{array}$ & - & DE F3 \\
\hline $\begin{array}{l}\text { R-DE-3/ } \\
\text { R-NQ-3 }\end{array}$ & $\begin{array}{l}\text { GGGGGAAGAGGAAGACGTCCGG } \\
\text { TCCCCCCAGGAGTTCAGGTGCTG }\end{array}$ & - & DE F3; NQ F3 \\
\hline $\begin{array}{l}\text { F-DE-4/ } \\
\text { F-NQ-4 }\end{array}$ & $\begin{array}{l}\text { GTTGCTITGATTACAACACTGGA } \\
\text { GAGAAATGCAGCATGTTGCTGATT }\end{array}$ & -- & DE F4; NQ F4 \\
\hline R-DE-4 & $\begin{array}{l}\text { GGGGGAAGAGGAAGACGTCCG } \\
\text { GTCCCCCCAGGAGTTCAGGTGCTG }\end{array}$ & S239D & DE F4 \\
\hline F-NQ-1 & $\begin{array}{l}\text { CAGAGCACGTACCGGGTGGT } \\
\text { CAGCGTCCTCACCGTCCTGCACCAG }\end{array}$ & N297Q & NQ F1 \\
\hline R-NQ-1 & $\begin{array}{l}\text { TGATCTACCCGCGCTCAGCCC } \\
\text { TGGGCGCATGCTCCTCGCGCTGTC }\end{array}$ & - & NQ F1 \\
\hline F-NQ-2 & $\begin{array}{l}\text { CGAGGAGCATGCGCCCAGGG } \\
\text { CTGAGCGCGGGTAGATCAGAGCACA }\end{array}$ & - & NQ F2 \\
\hline R-NQ-2 & $\begin{array}{l}\text { TACAAAGTGTTACCCCTCTAG } \\
\text { ACCTGGAAAGACCAGGCGGAGTT }\end{array}$ & - & NQ F2 \\
\hline F-NQ-3 & $\begin{array}{l}\text { GCCTGGTCTITCCAGGTCTAG } \\
\text { AGGGGTAACACTITGTACTGCGTT }\end{array}$ & - & NQ F3 \\
\hline R-NQ-4 & $\begin{array}{l}\text { AGGACGGTGAGGACGCTGACCACC } \\
\text { CGGTACGTGCTCTGGTACTGC }\end{array}$ & N297Q & NQ F4 \\
\hline
\end{tabular}

Underlined nucleotides depict mutated codons; sequences in red font indicate mutated nucleotides.

TABLE 2 | PIPE PCR fragments with accompanying specific PCR extension times for fragment amplification.

\begin{tabular}{lcc}
\hline Fragment & Approximate size (bp) & Extension time (s) \\
\hline NQ F1 & $\sim 2,000$ & 28 \\
NQ F2 & $\sim 2,000$ & 28 \\
NQ F3 & $\sim 2,000$ & 28 \\
NQ F4 & $\sim 2,600$ & 35 \\
DE F1 & $\sim 350$ & 5 \\
DE F2 & $\sim 3,150$ & 42 \\
DE F3 & $\sim 2,800$ & 35 \\
DE F4 & $\sim 2,400$ & 35
\end{tabular}


supernatants were harvested after 2 weeks of stable antibody expression without antibiotic selection. Monoclonal antibodies were purified using Pierce ${ }^{\mathrm{TM}}$ Protein A Columns, $1 \mathrm{~mL}$ (Thermo Fischer Scientific). Antibodies were eluted using acetate elution buffer ( $0.58 \%$ glacial acetic acid, $0.15 \mathrm{M}$ Sodium chloride) and neutralized with $120 \mu \mathrm{L}$ neutralization buffer $(1 \mathrm{M}$ Tris, $\mathrm{pH}=9)$. Purified antibodies were stored in PBS.

\section{Aleuria Aurantia Lectin (AAL) Western Blot}

Purified antibody samples (500 ng) were mixed with $4 \times$ Laemmli buffer (Bio-Rad) containing 10\% 2-mercaptoethanol and incubated at $95^{\circ} \mathrm{C}$ for $10 \mathrm{~min}$. Subsequently, the reduced samples were run on $4-15 \%$ precast polyacrylamide gels (BioRad) and semi-dry blotted using the Bio-Rad Trans-Blot ${ }^{\circledR}$ Turbo $^{\mathrm{TM}}$ Blotting System, according to the manufacturer's instruction. The membrane was then cut into two just above $35 \mathrm{kDa}$ to separate the antibody heavy chain $(50 \mathrm{kDa})$ and light chain $(25 \mathrm{kDa})$, using the PageRuler prestained protein ladder (Thermo Scientific) as a reference. Next, the membrane containing proteins above $35 \mathrm{kDa}$ was blocked using Carbo-Free ${ }^{\mathrm{TM}}$ Blocking Solution (Vectorlab) and the one containing proteins below $35 \mathrm{kDa}$-in $5 \%$ bovine serum albumin (BSA) solution in PBS $0.05 \%$ Tween 20 (PBST). For probing, the over-35 kDa membrane was incubated with $0.2 \mu \mathrm{g} / \mathrm{mL}$ biotinylated AAL in Carbo-Free ${ }^{\mathrm{TM}}$ Blocking Solution for $1 \mathrm{~h}$ at room temperature and subsequently washed in PBST $3 \times$ for 10 min. Next, the membrane was incubated with horseradish peroxidase (HRP)-conjugated streptavidin (Thermo Fischer Scientific, 1:30,000) for one hour, washed and developed with Enhanced Chemiluminescence (ECL, GE Healthcare). The under-35 kDa membrane was probed with rabbit anti-human-kappa light chain antibody (Abcam, 1:4,000) in PBST 5\% BSA for $1 \mathrm{~h}$ at room temperature, washed and incubated with anti-rabbit-IgG HRP antibody (Cell Signaling Technology, 1:2,000), washed again, and developed as above. The results were analyzed using the ImageJ software.

\section{Western Blot Semi-Quantitative Analysis}

The AAL signal values of the different protein bands (peak area) were normalized to the anti-kappa signal values (LC kappa). The AAL/LC kappa ratio values of anti-HER2 antibody variants were presented as a proportion (percentage) of the value of trastuzumab. Similarly, anti-CSPG4 antibody variant values were presented as a proportion of anti-CSPG4 WT.

\section{Evaluations of Antibody Yields by ELISA}

IgG antibody expression by Expi293F cells was monitored using a sandwich enzyme-linked immunosorbent assay (ELISA). Briefly, Maxisorp 96-well plates (Thermo Fischer Scientific) were coated overnight with $0.5 \mu \mathrm{g} / \mathrm{mL}$ mouse anti-human IgG1 antibody (Bio-Rad) in carbonate buffer. On the next day, the plate was washed with PBS 0.5\% Tween 20 (PBST) and unspecific binding was blocked using 2\% skim milk in PBST (blocking buffer). Trastuzumab (Herceptin ${ }^{\circledR}$, Roche) was used at as a standard at a starting concentration of $3 \mu \mathrm{g} / \mathrm{mL}$. All samples were diluted $(1: 1,000)$ in blocking buffer and incubated on the plate overnight. The plates were developed on the next day, following an incubation with anti-human IgG-HRP (Sigma) at a dilution of 1:5,000, using o-Phenylenediamine dihydrochloride (Sigma) as the HRP substrate. Optical density was measured using Fluostar ${ }^{\circledR}$ Omega Spectrophotometer (BMG Labtech), at 492 and $650 \mathrm{~nm}$, the latter used to subtract background absorbance. Standard curves were constructed on the Fluostar ${ }^{\circledR}$ Omega analysis software using a 4-parameter fit.

\section{Assessment of Antibody Binding to Cells by Flow Cytometry}

Recognition of FcyRs on fresh peripheral blood NK cells and of the target antigen on tumor cells by different anti-HER2 and anti-CSPG4 antibody variants were assessed through flow cytometric binding assays. Cells were detached, as described above, re-suspended in staining buffer (PBS, 2\% FCS) and incubated in 96-well round-bottom plates $\left(0.2 \times 10^{6}\right.$ cells per well $)$ on ice in the presence of the serially diluted antibody variants (concentration range $0.008-5 \mu \mathrm{g} / \mathrm{mL}$ ) for $30 \mathrm{~min}$ on ice. The cells were subsequently washed and incubated with $1 \mu \mathrm{g}$ per test FITC-conjugated goat anti-human IgG (Vector Laboratories Ltd.) on ice, for another $30 \mathrm{~min}$. After one wash, cells were analyzed on a BD LSRFortessaTM (BD Biosciences), using the High Throughput Sampler (HTS) option. The BD Cytofix/Cytoperm ${ }^{\mathrm{TM}}$ (Becton Dickinson) kit was used according to the manufacturer's instructions for Expi293F cell permeabilization and intracellular staining to detect antibody production. The results were analyzed using FlowJo software 7.6.5.

\section{Cell Proliferation Assay}

To determine the effect of anti-HER2 antibody variants on cell proliferation, 5,000 (BT-474) or 1,000 (SK-BR-3, MDA-MB-231, HCC1954) cells per well were plated in a 96-cell well tissue culture plates in complete medium and treated with the serially diluted antibodies (concentration ranges $0.0016-25 \mu \mathrm{g} / \mathrm{mL}$ ). Cell proliferation was assessed after 96 (BT474, MDA-MB-231) or 120 h (SK-BR-3, HCC1954), using the CellTiter $966^{\circledR}$ Aqueous One Solution Cell Proliferation Assay kit (Promega), according to the manufacturer's instructions. Cell densities were measured using Fluostar ${ }^{\circledR}$ Omega Spectrophotometer (BMG Labtech).

\section{Antibody-Dependent Cellular Cytotoxicity (ADCC) Assay}

ADCC assays were performed using the HER2-overexpressing BT-474 cells as target cells and fresh peripheral blood NK cells as effector cells. NK cells and cancer cells were mixed at E:T ratio 10:1 $\left(0.2 \times 10^{6} \mathrm{NK}\right.$ cells: $0.02 \times 10^{6}$ target cells $)$ in RPMI GlutaMAX $^{\mathrm{TM}}$ (Thermo Fischer Scientific) containing 2\% FCS (Thermo Fischer Scientific). They were incubated in 96-well round bottom plates for $4 \mathrm{~h}$ (Thermo Fischer Scientific) in the presence of serially diluted anti-HER2 antibody variants or isotype control antibodies (at concentrations ranging from $64 \mathrm{pg} / \mathrm{mL}$ to $5 \mu \mathrm{g} / \mathrm{mL}$ ). Cellular cytotoxicity was assessed 
using the Pierce LDH Cytotoxicity Assay Kit (Thermo Fischer Scientific), according to the manufacturer's instructions. Absorbance read out was measured at 490 and $680 \mathrm{~nm}$ using
Fluostar $^{\circledR}$ Omega Spectrophotometer (BMG Labtech) and \% cytotoxicity was calculated as per manufacturer's instructions using the following formula:

$$
\% \text { Cytotoxicity }=\left(\frac{\text { Experimental value }- \text { Effector Cells Spontaneous Control }- \text { Target Cells }}{\text { Target Cell Maximum Lysis Control }- \text { Target Cells Spontaneous Control }}\right) \times 100
$$

Half maximal effective concentration (EC50) values at which different anti-HER2 Fc variant antibodies induced ADCC were calculated using the GraphPad Prism software (version 6, GraphPad Software Inc., USA). The data were normalized to a maximal (detergent induced) and minimal (isotype control) cell lysis and analyzed using a non-linear regression model.

\section{Calcium Flux Assay}

Freshly isolated human NK cells were incubated with $1 \mathrm{nM}$ Indo- 1 calcium indicator (Thermo Fischer Scientific) for $30 \mathrm{~min}$ at $37^{\circ} \mathrm{C}$ in serum-free medium and subsequently washed and rested for $30 \mathrm{~min}$ in complete medium (42). Cells $\left(1 \times 10^{6}\right.$ cells per test) were incubated with anti-HER2 and anti-CSPG4 antibody variants at $15 \mu \mathrm{g} / \mathrm{mL}$ for $30 \mathrm{~min}$ at $37^{\circ} \mathrm{C}$, as above, and re-suspended in $500 \mu \mathrm{L}$ RPMI GlutaMAX ${ }^{\mathrm{TM}}$ (Thermo Fischer Scientific). Before acquisition each sample was warmed up to $37^{\circ} \mathrm{C}$ for exactly $5 \mathrm{~min}$. The sample was acquired for $30 \mathrm{~s}$ to measure basal fluorescence, then the FcRs on the surface of the NK cells were crosslinked by adding $5 \mu$ g goat anti-human IgG $\mathrm{F}\left(\mathrm{ab}^{\prime}\right) 2$ (Thermo Fischer Scientific). Each sample was acquired for 5 min on BD LSRFortessa ${ }^{\mathrm{TM}}$ (BD Biosciences) with the violet laser $(405 \mathrm{~nm})$ turned off to avoid interference. Ionomycin at $1 \mu \mathrm{g} / \mathrm{mL}$ was used as a positive control. Results were analyzed using FlowJo software version 8.7.

\section{Human Specimens}

Blood cone samples from anonymized donors were purchased from the National Health Service Blood and Transplant Service, United Kingdom. Sample processing was supported through a local ethical framework conducted in accordance with the Helsinki Declaration and approved by the NHS Research Ethics Committee, Guy's and St. Thomas' NHS Trust ("Immunopathogenesis and Molecular Biology in Breast Cancer Subtypes," REC reference number: 13-LO-1248).

\section{RESULTS}

\section{Antibody Fc Region Manipulation Design}

First, we devised a cloning strategy that allows the manipulation of monoclonal antibody Fc regions in order to influence FcRs binding properties and consequently antibody effector functions. Alongside WT equivalents, we generated Fc-mutant variants designed either to have diminished or enhanced binding to FcRs on human immune effector cells, and we exemplified this strategy by engineering panels of antibody clones that recognize two cancer-associated antigens.
We initially employed WT IgG1 antibody heavy and light chain fragments incorporated in pVitrol-hygro-mcs vectors (Figure 1A). We then utilized these vectors as templates in four separate PIPE PCRs in order to generate linear fragments carrying specific Fc region point mutations (Figures 1B,C). Point mutations were introduced using mutagenic PIPE primers (Table 1; Table S1 in Supplementary Material). Mutations were designed to either reduce [N297Q (NQ), Figure 1B] or enhance [S239D/ I332E (DE), Figure 1C] binding of the antibody Fc to FcyRs (Fc gamma receptors) on human effector cells. Since Asn297 is a conserved glycosylation site for the human IgG1 Fc domain, we mutated this to Gln. This is expected to lead to aglycosylation and a conformational change which can impair binding to Fc $\gamma$ Rs $(26,28)$. By contrast, we designed S239D/I332E (DE) mutated IgG1 Fc regions to have increased binding to the Fc $\gamma$ RIII compared to WT IgG1 antibodies.

To generate the N297Q mutant antibody variants designed to have reduced binding to FcRs (Figure 1B), we linearized the pVitro1 WT constructs through PIPE PCR (see Table 1 for primer pairs), yielding Fragments 1, 2, 3, and 4. Fragment 1 was generated to carry CAG $(\mathrm{Q})$ instead of AAC (N) at positions 889-891. Shortened extension times and lack of final extension step favored the PIPE process during the PCR. Therefore, the Fragment 1 final product had 5' PIPE overhangs ("sticky ends") but also carried the desired CAG codon. Similarly, we generated Fragment 4 with 5 ' overhangs and the desired mutated codon. The other two fragments, Fragment 2 and Fragment 3, were as well amplified with 5' PIPE overhangs but without point mutations.

The S239D/I332E mutants designed to yield antibodies with enhanced FcR binding were generated in a similar manner (see Table 1 for primer pairs). The pVitro1 WT constructs were linearized through PIPE PCR to favor the occurrence of sticky ends for PIPE cloning (Figure 1C). All fragments were amplified with PIPE 5' overhangs; however, Fragment 1 carried both the GAC (D) codon instead of the WT TCA (S) codon, and the GAA (E) codon instead of the WT ATC (I) codon (positions 877-879 and 994-996, respectively); Fragment 2 carried the GAA (E) codon instead of ATC (I) codon; and Fragment 4 carried GAC (D) codon instead of TCA (S) codon.

The primers used for the generation of both N297Q (NQ) and S239D/I332E (DE) Fc mutants are designed to be universal and can be used for the generation of NQ and DE mutant versions of any IgG1 antibody cloned into pVitro1-hygro-mcs (see Table 2 for lengths of the pVitro1 PIPE fragments and extension times for amplifications).

Following amplification, linear pVitrol fragments were treated with DpnI enzyme to digest any remnants of the pVitro1 WT construct used as a template in the PCR (Figure 1D). All four fragments were then mixed together unpurified, thus eliminating 


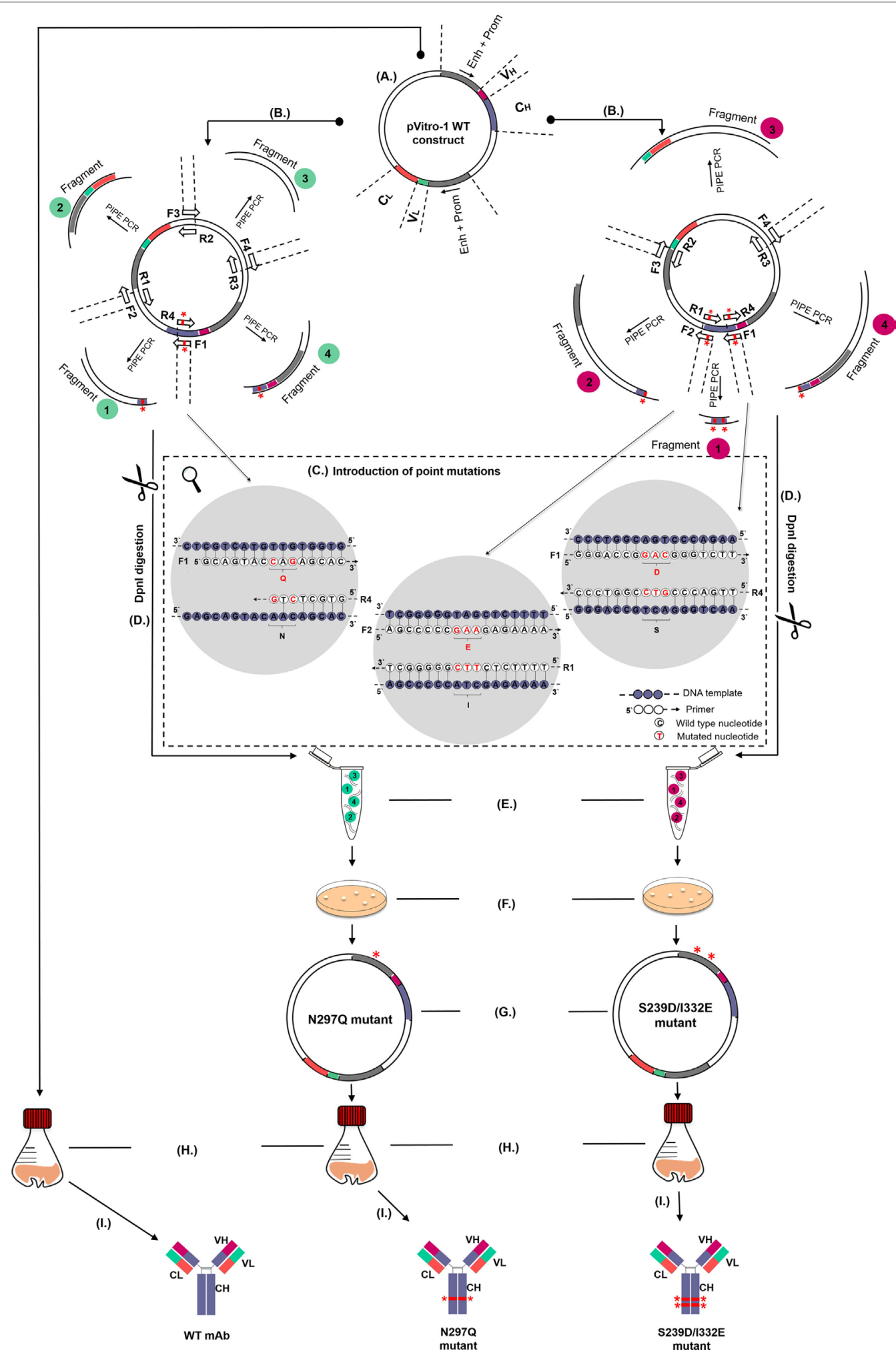

FIGURE 1 | Schematic representation of the pipeline for generation and production of wild-type (WT) and Fc mutant IgG antibodies. (A) WT antibody construct in pVitro1-hygro-mcs. (B) Polymerase incomplete primer extension (PIPE) PCR linearization and mutagenesis of the WT construct to generate pVitro1 DNA fragments carrying the N297Q (left, fragments 1 and 4) or S239D/I332E (right, fragments 1, 2, and 4) mutations. Mutations indicated by "*”. (C) Introduction of mutations in WT constructs through mutagenic PIPE primers. (D) Dpnl digestion. (E) Enzyme-independent assembly of the linear pVitro1 fragments. (F) Bacterial transformation of the assembled constructs. (G) Confirmation of the insertion of desired mutations. (H,I) Recombinant expression in Expi293F cells (H) and purification (I) of antibody WT and mutant variants. 
the need to perform PCR clean up or to use ligation enzymes. The mixtures were incubated at room temperature (Figure 1E) and transformed into competent bacteria (Figure 1F). Correct transformants were verified through Sanger sequencing (Figure 1G). Expi293F cells were transfected with the pVitrol mutant constructs in $30 \mathrm{~mL}$ working volumes (Figure 1H) and antibodies were secreted in culture supernatants (Figure 1I).

Overall, this strategy facilitates the manipulation of monoclonal antibody Fc regions to allow the generation of mutant versions of any IgG1 antibody clone.

\section{Generation of Anti-HER2 and Anti-CSPG4 N297Q and S293D/I332E IgG1 Mutant Constructs}

Using our pipeline, we generated WT, N297Q (NQ), and S293D/ I332E (DE) mutant antibodies recognizing two cancer antigens

(i) the human epidermal growth factor receptor 2 (HER2/neu)

(3), known to be overexpressed by $25 \%$ of breast carcinomas and

(ii) the CSPG4, reported to be overexpressed in $70 \%$ of melanomas, a proportion of triple-negative breast cancers, and other solid tumors $(41,43,44)$. In order to produce anti-HER2 IgG1 WT antibody, we used the variable regions of the 4D5-8 therapeutic antibody clone (trastuzumab) $(2,4,45)$. The sequence was manually codon-optimized (Figure S1 in Supplementary Material), and cloned into the pVitro1-hygro-mcs vector (36). The anti-CSPG4 IgG1 WT construct was derived using the variable regions of a murine antibody (46) and cloned into pVitro1-hygro-mcs (36). The pVitro1 WT constructs were used as templates for the generation of the corresponding mutant variants. The DNA products of the mutagenic PIPE PCRs were visualized using agarose gel electrophoresis (Figure 2), confirming that the fragments were of the expected sizes.

All four mutant constructs were successfully cloned on first attempt and between 1 and 15 colonies were analyzed for the different constructs (Table S2 in Supplementary Material). The desired mutations were present in all the screened plasmids (each purified from a single colony) and no background contamination with the WT construct was observed. These findings suggest high mutagenesis efficiency for this cloning approach.

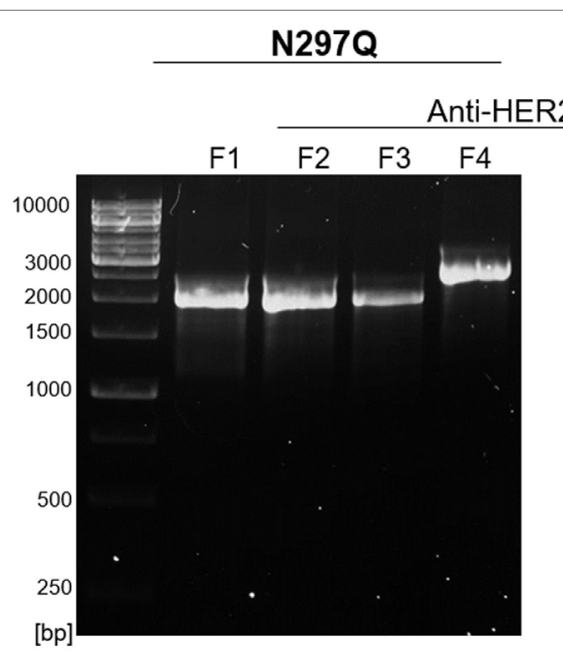

Anti-CSPG4 constructs
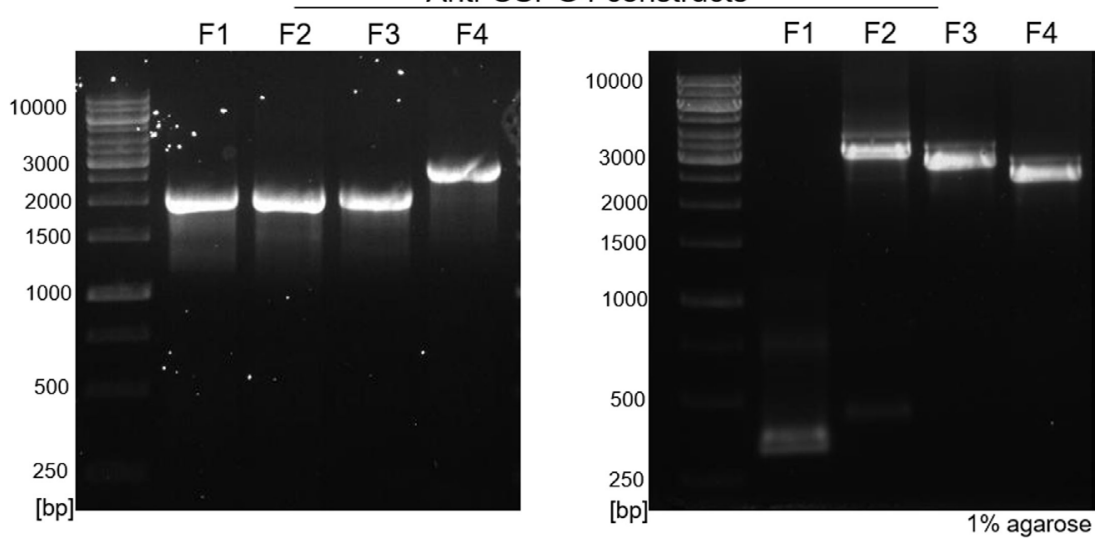

FIGURE 2 | Agarose gel electrophoresis of polymerase incomplete primer extension (PIPE) PCR fragments for the generation of anti-HER2 and anti-CSPG4 N297Q (NQ) and S293D/I332E (DE) Fc mutant IgG1 antibodies. O'GenerulerTM 1 kb DNA ladder (Thermo Fischer Scientific) was used as a molecular weight marker. The lanes labeled F1-4 represent the NQ and DE PIPE PCR fragments 1-4, depicted in Figure 1. The expected molecular weights (in bp) of each fragment are listed in Table 2. 


\section{Optimized Antibody Production with the Expi293F Expression System}

We produced monoclonal antibodies both by using a previously described HEK293-F system as well as by employing the cloning approach described herein with the human embryonic kidney derivative cell line Expi293F. Antibody production with the previous method in HEK293-F cells was initiated using $30 \mathrm{~mL}$ shaker flask cultures under selection for 2 weeks, followed by a 2 -week scale up to $500 \mathrm{~mL}$ shaker flask cultures. With the previous platform, after 4 weeks, we obtained an average of $13 \mu \mathrm{g} / \mathrm{mL}$ of anti-CSPG4 WT (by ELISA). By contrast, using the present transient expression Expi293F platform, we produced an average of $130 \mu \mathrm{g} / \mathrm{mL}$ anti-CSPG4 WT and $160 \mu \mathrm{g} / \mathrm{mL}$ anti-HER2 WT antibodies using only $30 \mathrm{~mL}$ shaker flask cultures volumes within 5-7 days post-transfection (detected by ELISA) (Figure 3A).

To evaluate the rate of transfection efficiency, we used flow cytometry to analyze the expression of IgG by permeabilized Expi293F cells 3 days after transfection with the anti-HER WT, DE, and NQ constructs (Figure 3B). A large proportion ( $\geq 98 \%$ ) of transfected Expi293F cells was positive for human IgG, indicating a high transfection efficiency rate. To investigate whether the addition and timing of antibiotic selection (Hygromycin B) to Expi293F cell cultures could affect antibody yields, we expressed anti-HER2 WT antibody with or without the addition of Hygromycin B at different times following transfection and found that addition of Hygromycin B did not affect purified anti-HER2 antibody yields (Figure 3C). To then determine the optimal time to harvest the supernatants, we monitored the concentrations of anti-HER2 WT and anti-CSPG4 WT antibodies over time by ELISA. For both antibodies, the maximum production yields were reached between 5 and 7 days post-transfection (Figure 3D).

We then measured total antibody yields by Expi293 cells after purification of anti-HER2 and anti-CSPG4 variants. We obtained an average of $56 \mu \mathrm{g} / \mathrm{mL}$ anti-HER2 DE, $62 \mu \mathrm{g} / \mathrm{mL}$ anti-HER2 NQ (Figure 4A, left), $44 \mu \mathrm{g} / \mathrm{mL}$ anti-CSPG4 DE, and $73 \mu \mathrm{g} / \mathrm{mL}$ anti-CSPG4 NQ (Figure 4A, right). We then confirmed that Fc mutations did not impair the binding of antibodies to protein A used for antibody purification: no significant differences in protein yields of either anti-HER2 DE (Figure 4B, left) or anti-HER2 NQ variants (Figure 4B, right) were measured after purification by protein A column, or by KappaSelect column, which binds antibody kappa light chains. We concluded that none of the mutations could alter antibody binding to either matrix and, thus, the purification method did not appear to influence antibody yields.

Next, the integrity and purity of different anti-HER2 and anti-CSPG4 antibody variants were confirmed through sodium dodecyl sulfate polyacrylamide gel electrophoresis (SDS-PAGE) under non-reducing (Figure 4C, top) and reducing (Figure 4C, bottom) conditions. All antibodies migrated according their expected approximate molecular weights of $\sim 150 \mathrm{kDa}$ (nonreducing conditions) and no other contaminating proteins or antibody fragments were observed. Under reducing conditions, the heavy chains of the WT and DE variants of both antibodies migrated according to the expected molecular weight of $50 \mathrm{kDa}$. Anti-HER2 and anti-CSPG4 NQ variants exhibited increased mobility compared with the WT and DE analogs, in accordance with previous reports (28). The light chains of all the variants were found to be of the expected size of $25 \mathrm{kDa}$.

To ascertain whether different Fc mutations influence glycosylation and to simultaneously evaluate the fucosylation patterns of the anti-HER2 and anti-CSPG4 variants, we probed purified antibody samples with AAL (fucose specific, Figure 4D). We used an antihuman kappa chain antibody as a loading control (Figure 4D, bottom strips). We observed no AAL signal with the anti-HER2 and anti-CSPG4 NQ variants, confirming that the introduced N297Q amino acid substitution has resulted in lack of core glycosylation (Figure 4D, top panel). We performed semi-quantitative analysis of the AAL Western blot data using the ImageJ software (Figure 4E). The values obtained with the NQ variants were close to background. No significant differences were observed between WT and DE mutant antibodies (both anti-HER2 and anti-CSPG4 variants). These findings suggest that mutating the $\mathrm{Fc}$ region of IgG1 at position 297 disrupts a conserved glycosylation site, most likely eliminating core glycosylation, while mutations at positions 293 and 332 do not affect the decoration of the core glycan with fucose.

Therefore, we confirmed the implementation of an optimized Expi293F expression platform with additional features and which outperforms that previously reported. Key attributes are five-fold: namely (i) provision for generation of mutant antibody variants; (ii) high mutagenesis efficiency; (iii) high transfection efficiency (eliminating the need for antibiotic selection); (iv) up to 10 -fold higher antibody yields in $\sim 17$-fold smaller $(30 \mathrm{~mL}$ ) culture volumes; and (v) 3-fold reduced time frame (12 days) for implementation from concept to purified antibody (Table 3).

\section{Fc Mutants Retain Fab-Mediated Binding to Antigens but Exhibit Differential Fc-Mediated Receptor Recognition Compared with WT Antibodies}

We next investigated the target antigen recognition and binding properties of engineered antibody variants against different cancer cell lines expressing cell surface HER2 (Figure 5A; Figure S2 in Supplementary Material) or CSPG4 (Figure 5B). All HER2 variants recognized HER2 on BT-474 (top left), SK-BR-3 (top right), ZR-75-30 (bottom left) and HCC1954 (bottom right) breast cancer cell lines, and bound in a dose-dependent manner and with comparable kinetics to the commercially produced trastuzumab (Herceptin ${ }^{\circledR}$, Roche). Similarly, for the engineered antibodies recognizing CSPG4 (Figure 5B), no differences were observed in their binding characteristics to the CSPG4-overexpressing CSPG4 knock-in MDA-MB-231 (top left), and natural lower-expressing MDA-MB-231, HTB-26 (top right), Hs 578T (bottom left), and BT549 (bottom right) breast carcinoma cell lines.

We then investigated the binding characteristics of anti-HER2 and anti-CSPG4 Fc variants to Fc $\gamma$ RIII, the Fc $\gamma$ receptor expressed by NK cells (47) (Figure 5C). Fluorescence intensities observed for human peripheral blood NK cells incubated with anti-HER2 (top) and anti-CSPG4 (bottom) NQ variants were similar to those measured for the secondary anti-human kappa chain APC-conjugated antibody control at all concentrations tested, suggesting that the NQ mutation resulted in impaired binding to FcyRIII. Binding of the WT anti-HER2 antibodies, including 


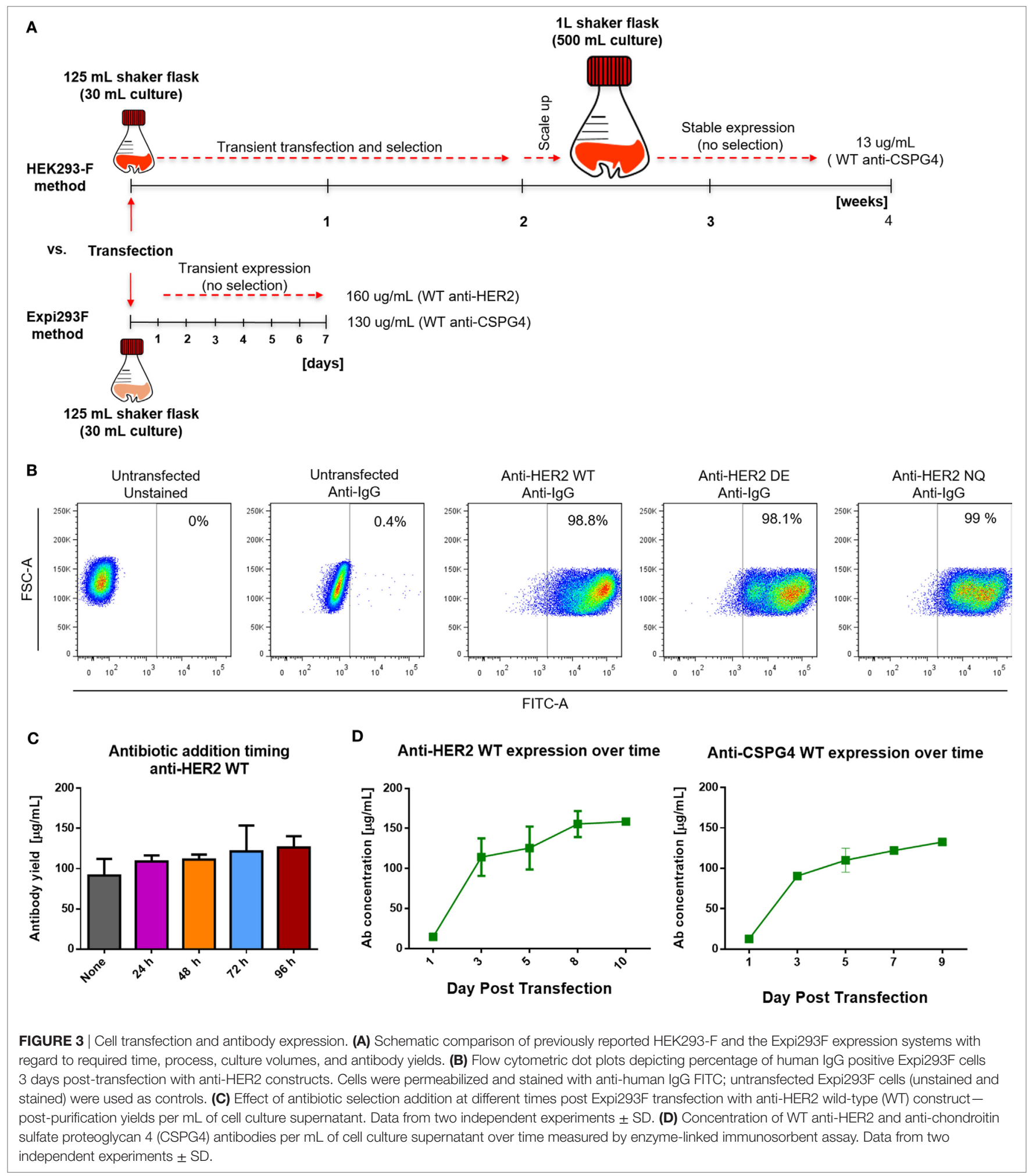

the commercially available trastuzumab (Herceptin ${ }^{\circledR}$ ) to human NK cells were detected only at the highest concentrations tested ( 1 and $5 \mu \mathrm{g} / \mathrm{mL}$ ). Similarly, the anti-CSPG4 WT antibody only bound to NK cells at high $(5 \mu \mathrm{g} / \mathrm{mL})$ concentrations. By contrast, the anti-HER2 and anti-CSPG4 DE variants displayed up to 7-fold (anti-HER2) and 17-fold (anti-CSPG4) higher binding to Fc $\gamma$ RIII on NK cells compared with binding of WT antibodies at $5 \mu \mathrm{g} / \mathrm{mL}$ concentrations to Fc $\gamma \mathrm{RIII}$ (Figure 5C). 

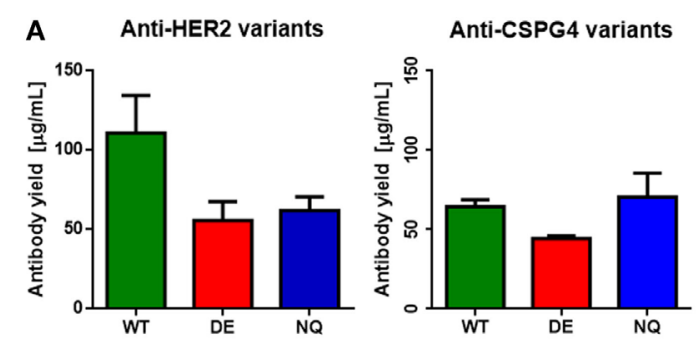

C
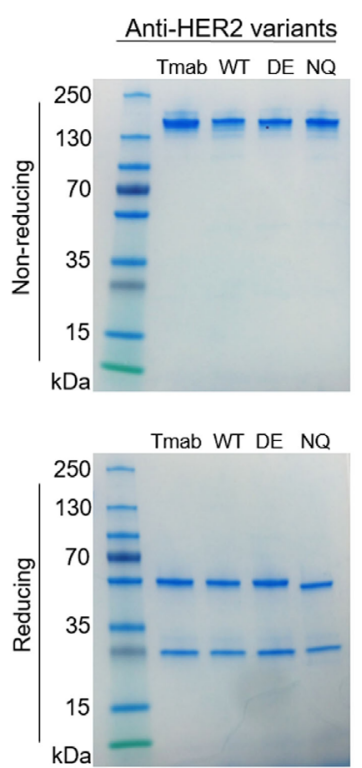

Anti-CSPG4 variants
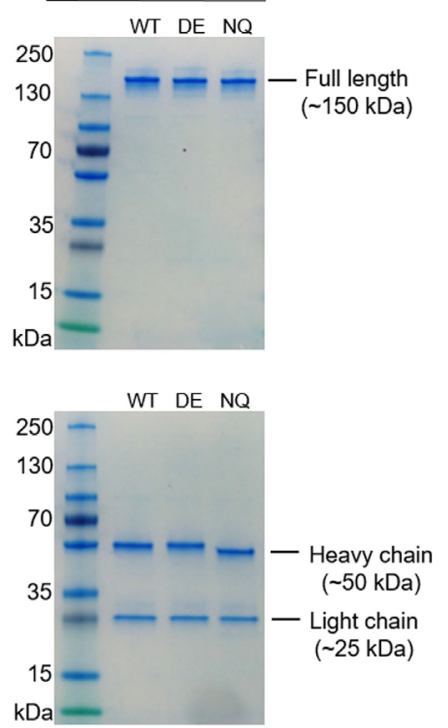
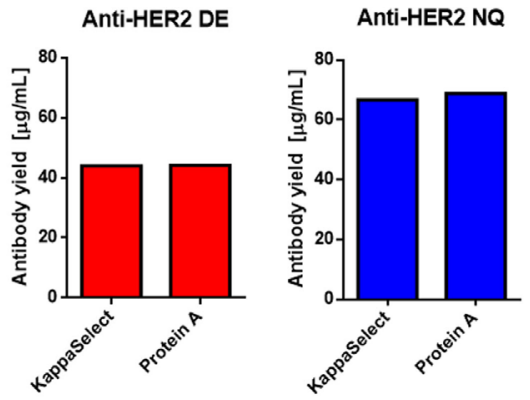

D

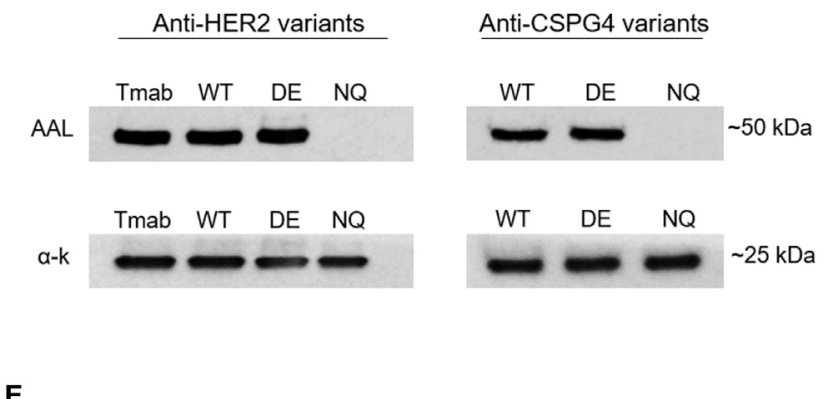

AAL WB: anti-HER2 variants

AAL WB - anti-CSPG4 variants
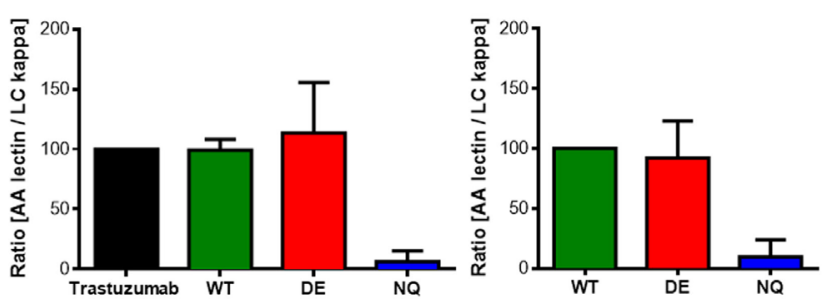

FIGURE 4 | Purified antibody evaluations. (A) Wild-type (WT) and mutant anti-HER2 and anti-CSPG4 antibody yields per mL of cell culture supernatant after purification (data from two independent experiments \pm SD). (B) Comparison of anti-HER2 mutant antibody yields after purification using HiTrap Kappa Select (GE Healthcare) or Protein A (Pierce ${ }^{\mathrm{TM}}$ ) columns. (C) Sodium dodecyl sulfate polyacrylamide gel electrophoresis visualization of purified anti-HER2 and antichondroitin sulfate proteoglycan (CSPG4) WT and Fc mutant antibodies under non-reducing (top) and reducing (bottom) conditions. PageRulerTM pre-stained protein ladder (Thermo Fischer Scientific) was used as molecular weight reference. Bands were visualized using InstantBlue ${ }^{\text {TM }}$ protein stain (Expedeon). (D) Aleuria Aurantia Lectin (AAL) Western blot demonstrating fucosylation patterns of anti-HER2 (top left) and anti-CSPG4 (top right) Fc variants. Anti-human kappa chain antibody was used as a loading control (bottom panels). (E) Quantification of AAL Western blot signal using the ImageJ software. The AAL signal was normalized against the signal obtained with the anti-kappa chain antibody. The ImageJ peak area value of trastuzumab (Herceptin ${ }^{\oplus}$, Roche) was considered a $100 \%$ and the peak area values of the other anti-HER2 variants were presented as a proportion of the first value. The values of anti-CSPG4 DE and NQ were calculated accordingly as a proportion of anti-CSPG4 WT. Data from three independent experiments \pm SD.

TABLE 3 | Characteristics of the Expi293F vs. the HEK293-F cloning/expression platforms.

\begin{tabular}{|c|c|c|}
\hline Expression host & Expi293F & HEK293-F \\
\hline $\begin{array}{l}\text { Wild-type (WT) antibody polymerase } \\
\text { incomplete primer extension (PIPE) cloning }\end{array}$ & Yes & Yes \\
\hline Generation of Fc mutants & Yes & No \\
\hline Expression culture conditions & Serum free & $10 \%$ FBS \\
\hline Expression system type & Transient & Stable \\
\hline Antibody concentration (sup) & $\begin{array}{l}130 \mu \mathrm{g} / \mathrm{mL} \\
\text { (anti-CSPG4 WT) }\end{array}$ & $\begin{array}{l}13 \mu \mathrm{g} / \mathrm{mL} \\
\text { (anti-CSPG4 WT) }\end{array}$ \\
\hline Working culture volume (expression) & $30 \mathrm{~mL}$ & $500 \mathrm{~mL}$ \\
\hline Time required for cloning/sequencing verification & 3 days & 3 days \\
\hline $\begin{array}{l}\text { Time required for large scale plasmid DNA } \\
\text { production/transfection }\end{array}$ & 2 days & 2 days \\
\hline Time required for expression/purification & 1 week & 4 weeks \\
\hline Total time required (whole platform) & 12 days & 33 days \\
\hline
\end{tabular}

These findings suggest that while Fc-mutated antibodies retain Fab-mediated recognition of target antigen-expressing cancer cells, DE mutant antibodies have enhanced, and NQ mutants have diminished binding to FcyRIII on human primary NK cells compared with their WT equivalents.

\section{DE Mutant Antibodies Have Enhanced, While NQ Mutants Have Diminished Ability to Induce Fc-Mediated Activation of NK Cells Compared with WT Antibodies}

To further assess the ability of antibody variants to engender NK effector cell activation through engagement of Fc $\gamma$ RIII, we measured calcium ion influx by cross-linking with polyclonal anti-IgG antibodies to mimic immune complex formation. 

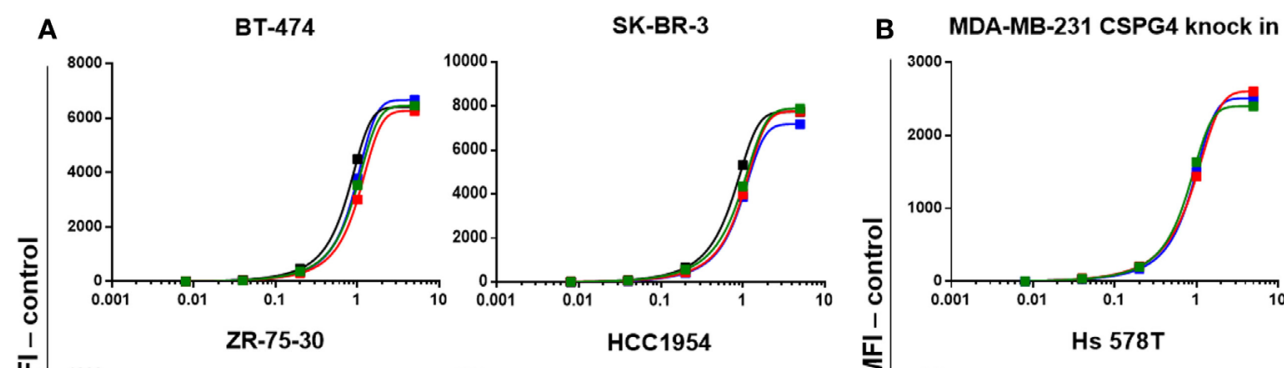

MDA-MB-231 HTB-26
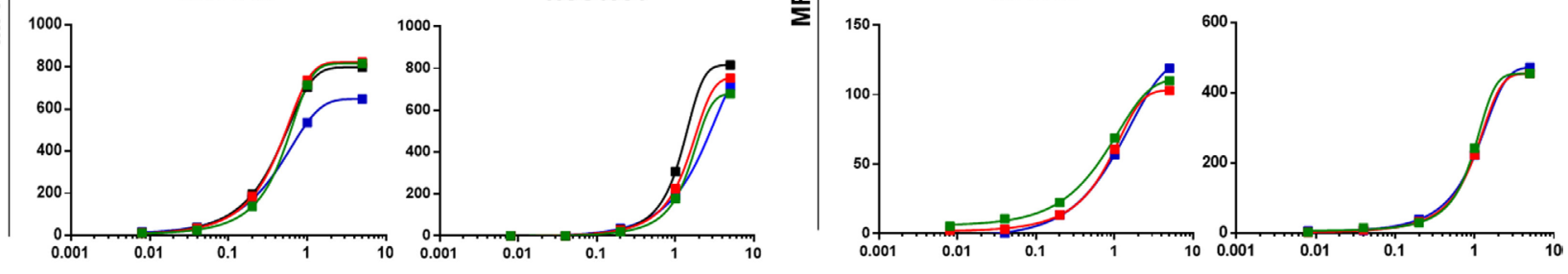

Ab concentration $[\mu \mathrm{g} / \mathrm{mL}]$

Ab concentration $[\mu \mathrm{g} / \mathrm{mL}]$
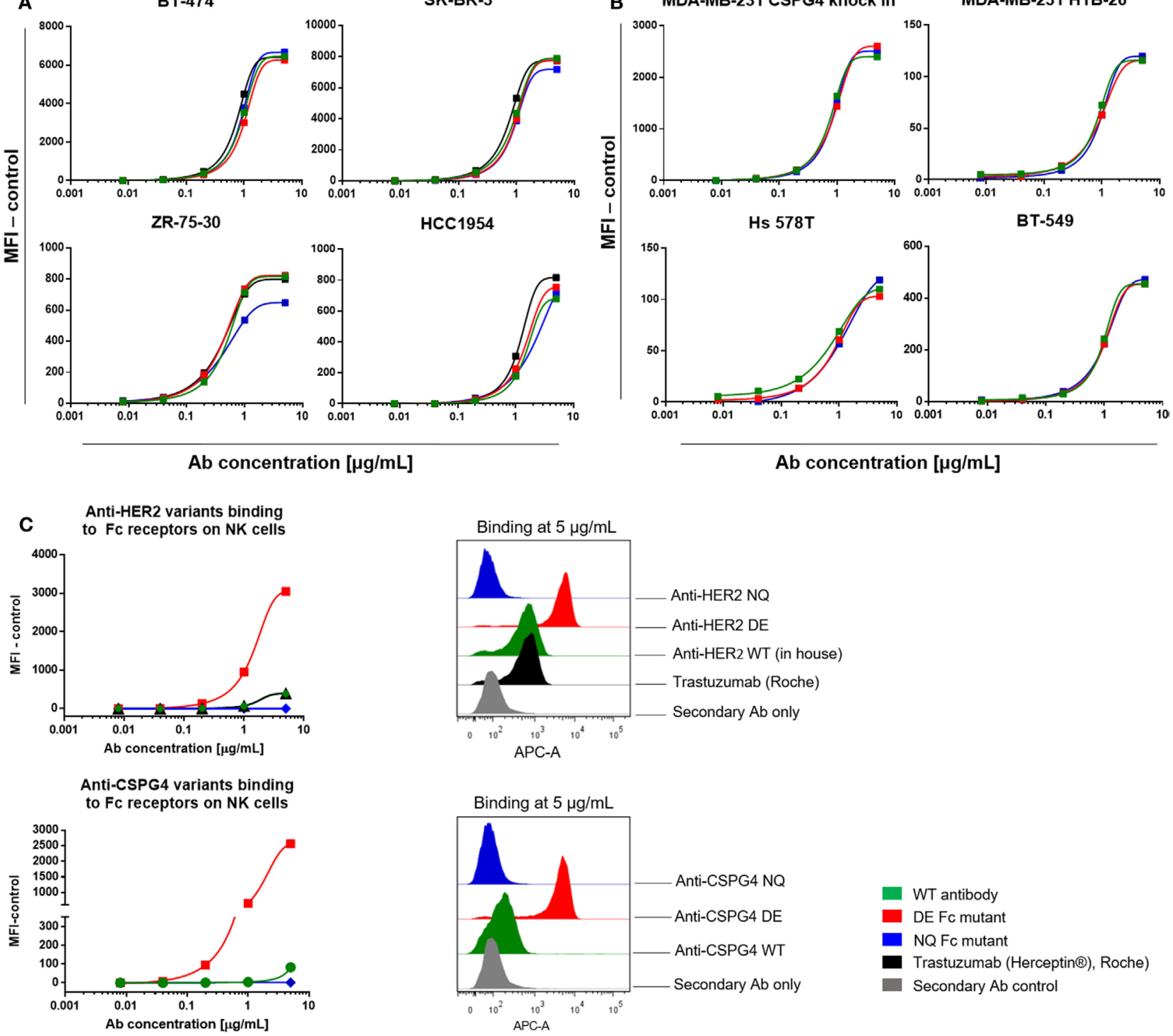
A

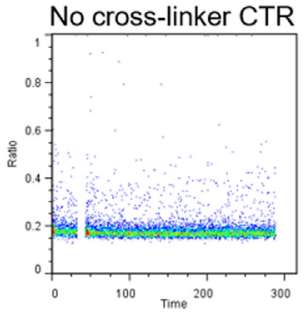

Anti-HER2 variants
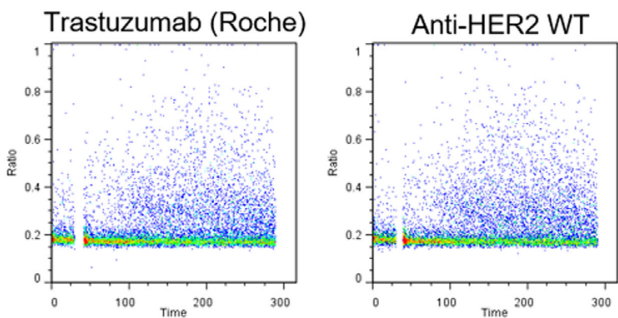

Anti-HER2 DE
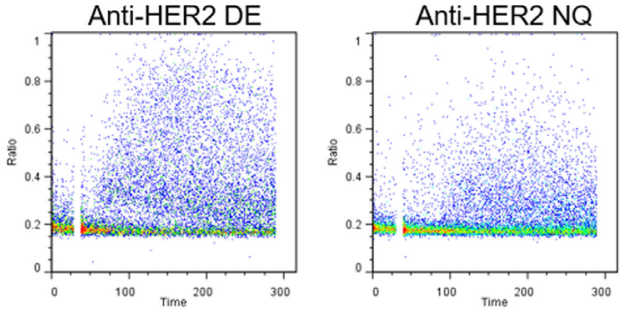

B
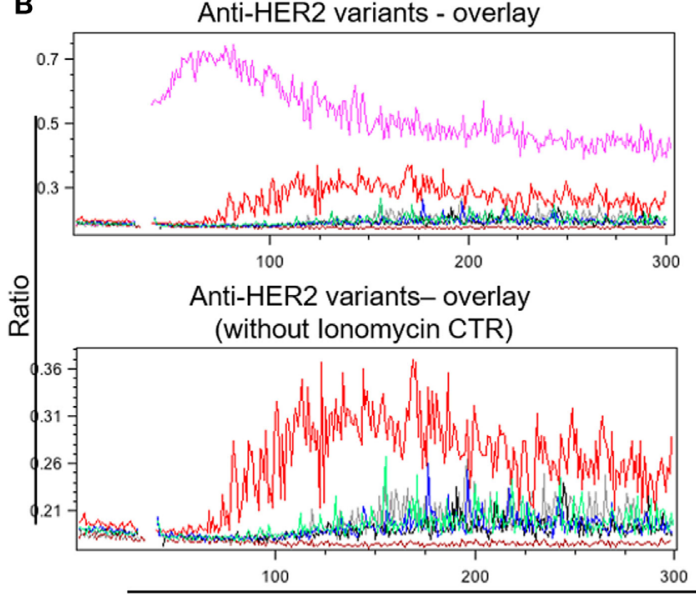

Time lonomycin CTR

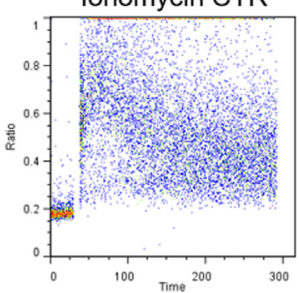

Anti-CSPG4 variants
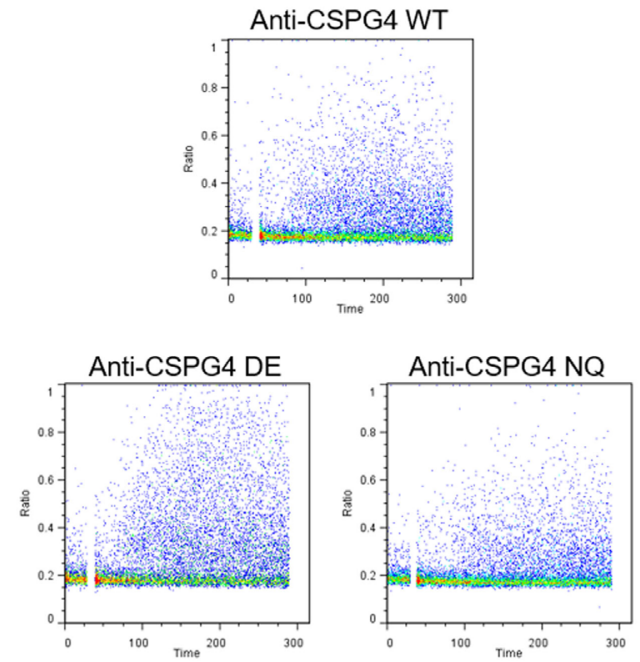

Anti-CSPG4 variants - overlay

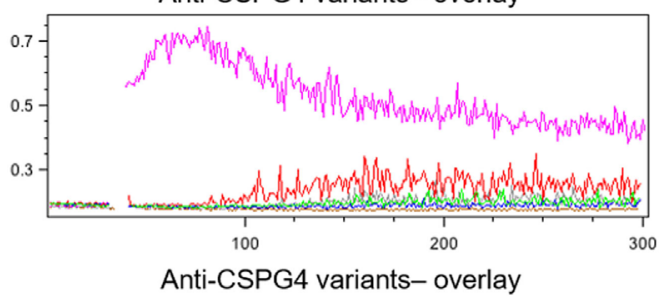

Anti-CSPG4 variants- overlay

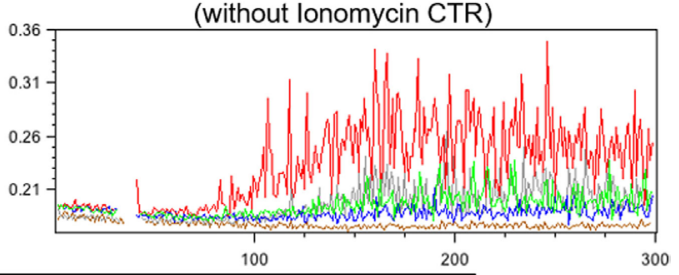

No cross-linker CTR

Cross-linker only CTR

Ionomycin CTR

WT antibody

DE Fc mutant

- NQ Fc mutant

- Trastuzumab (Herceptin ${ }^{\circ}$, Roche)

FIGURE 6 | Antibody Fc-mediated calcium mobilization of human NK cells. (A) Flow cytometric dot plot graphs of $\mathrm{Ca}^{++}$flux assay measurements showing activation of NK cells pre-incubated with different anti-HER2 Fc (left) and anti-chondroitin sulfate proteoglycan 4 (CSPG4) (right) Fc variants after cross-linking with a polyclonal anti-lgG antibody. $\mathrm{Ca}^{++}$flux into the cells was visualized through the increase in the DAPI/Indo-1 (blue) ratio over time. (B) Histogram overlay demonstrating the differences in $\mathrm{Ca}^{++}$influx between different anti-HER2 (left) and anti-CSPG4 (right) antibody variants depicted as the changes in the DAPI/Indo-1 Blue fluorescence ratio over time. The top overlays include all antibody variants and controls and the bottom exclude the ionomycin control to more clearly demonstrate the differences between the antibody variants on a smaller scale. Data representative of three independent experiments. 
We, therefore, examined whether these attributes are retained by the anti-HER2 Fc variants. WT and mutant anti-HER inhibited the proliferation of the HER2-overexpressing BT-474 and SK-BR-3 breast cancer cells in a dose-dependent manner, and with comparable potency to those of the clinically available trastuzumab (Herceptin $\left.{ }^{\circledR}\right)$. None of the variants could reduce the proliferation of the low HER2-expressing triple-negative MDA-MB-231 or of the trastuzumab-resistant HCC1954 breast cancer cell lines (Figure 7A) (49). We, therefore, concluded that Fc-engineered antibodies can retain the direct Fab-mediated effects of the original unmodified clone.

A known anti-tumor mechanism of action of trastuzumab (Herceptin ${ }^{\circledR}$ ) is the ability to trigger antibody-dependent cellular cytotoxicity (ADCC) of HER2-expressing cancer cells mediated by NK cells $(11,50)$. Therefore, we studied the potency of different anti-HER2 Fc variants to induce tumor cell cytotoxicity (ADCC) of the HER2-overexpressing BT-474 cells (target cells) mediated by fresh peripheral blood NK cells from three different donors (effector cells) (Figure 7B) (51-53). The in-house produced anti-HER2 WT antibody and trastuzumab (Herceptin ${ }^{\circledR}$ ) showed similar tumor cell killing potencies mediated by NK cells from all three human donors. Anti-HER2 DE induced higher tumor cell killing at significantly lower concentrations than WT antibodies. All antibodies showed similar levels of ADCC at saturating concentrations $(5 \mu \mathrm{g} / \mathrm{mL})$. In line with diminished binding to FcyRIII on the surface of NK cells, the anti-HER2 NQ mutant IgG1 failed to induce any tumor cell killing above controls (EC50 of variants for each independent experiment, Figure 7C).

Furthermore, we tested the potency of anti-HER2 variants to trigger NK cell-mediated ADCC against cancer cells that express low levels of the target. We chose the triple-negative breast cancer cell line MDA-MB-231 known to express very low levels of HER2/neu (Figure 7D), and the HER2-overexpressing cell line BT-474 to compare the effects of the target expression on ADCC levels induced by NK cells from the same donors (Figure 7D, Donors 4 and 5). We observed no or very low ADCC against MDA-MB-231 with all the variants (Figure 7, top panels), while against BT-474, anti-HER2 DE, WT, and trastuzumab induced dose-dependent tumor cell lysis (Figure 7D, bottom panels), consistent with the findings depicted in Figure 7B.

Therefore, while antibody Fab-mediated direct effects are not affected, Fc-modified antibody variant engineering allows the manipulation of antibody binding kinetics to effector cells, and can alter antibody functional capacity and potency to mediate immune effector cell activation and NK cell-mediated cytotoxicity of tumor cells.

\section{DISCUSSION}

With monoclonal antibody therapies firmly established as part of the standard care of treatment for solid tumors and hematological malignancies (54-56), designing antibodies to engender well-defined Fab-mediated and Fc-mediated anti-cancer properties is highly desirable. Specifically, Fc-mediated effects can have a major impact on the ability of antibodies to engage cells of the immune system and can influence their anti-tumor functions and efficacy.
Here, we designed and implemented a novel seamless cloning and expression platform for the generation of a panel of anticancer monoclonal antibodies with modified human Fc regions. We evaluated the functional impact of antibody engineering on antibody Fab- and Fc-mediated functions. This strategy allows the generation of WT and Fc mutant antibodies of any specificity at high mutagenesis and transfection efficiency, short time frames for cloning and production, and high yields of pure material. Compared to WT antibodies produced using a previous cloning approach, this represents 10 -fold increased yields at a 3 -fold reduced time frame of 12 days from design to purified antibody material (Table 3). This approach permits the generation of Fc-modified variants of any antibody clone and may find wide applications in antibody engineering and functional screening.

Compared with existing mutagenesis cloning methods, our approach is unique in combining the following features: (i) high efficiency; (ii) no need of restriction or ligation enzymes; (iii) requirement for only a single step PCR; (iv) designed for mutagenesis/cloning oflarge expression ready plasmid constructs; (v) employs universal primers which could be applied to any IgG1 antibody construct; and (vi) applicability for the generation of different versions of the same antibody construct $(36,37,40,57)$. These features, combined with rapid, small volume, and high yield transient expression in mammalian Expi293F cells constitute a unique and novel methodology which can facilitate selection of therapeutic antibody candidates with the most suitable attributes by employing mechanistic and potency evaluations.

While all antibody variants retained recognition of target antigens expressed on tumor cells, engagement of Fc $\gamma$ Rs on human primary NK cells was affected in Fc-mutated variants. The DE and NQ mutants showed enhanced and diminished binding properties, respectively, compared with binding of WT antibodies, consistent with previous findings (58). Here, binding studies of the Fc variants were conducted by flow cytometry on natively expressed FcRs and in the presence of endogenous immunoglobulins on the surface of fresh human NK cells. Hence, our 7- to 17-fold increased affinity of the DE variants compared with native antibodies may underestimate absolute increased affinities, previously measured with recombinant FcyRIIIa (58). Furthermore, although we engineered our antibody panels for each clone to be of the same isotype, with identical Fc region sequences, we observed that DE mutations improved the binding of anti-CSPG4 to NK cells more than the same mutations improved the binding of anti-HER2 enhanced DE variant. It is possible that these differences may depend on the antibody Fab regions and that mutating $\mathrm{Fc}$ regions in an identical way could still result in different Fc-mediated properties for different antibodies and merits further study. We also found differences in enhanced binding between DE and WT antibodies with different donors. It is, therefore, possible that enhanced kinetics would also be subject to donor-dependent effects and this requires investigation.

When we interrogated antibody Fc-mediated NK cell activation, we found enhanced calcium mobilization by mutant antibodies with high FcR-binding attributes. Furthermore, we observed low levels of Calcium influx triggered by endogenous IgGs on the surface of NK cells, which did not increase after the cells were incubated with WT antibodies. This may represent a 
A

Antibody Fab-mediated effects
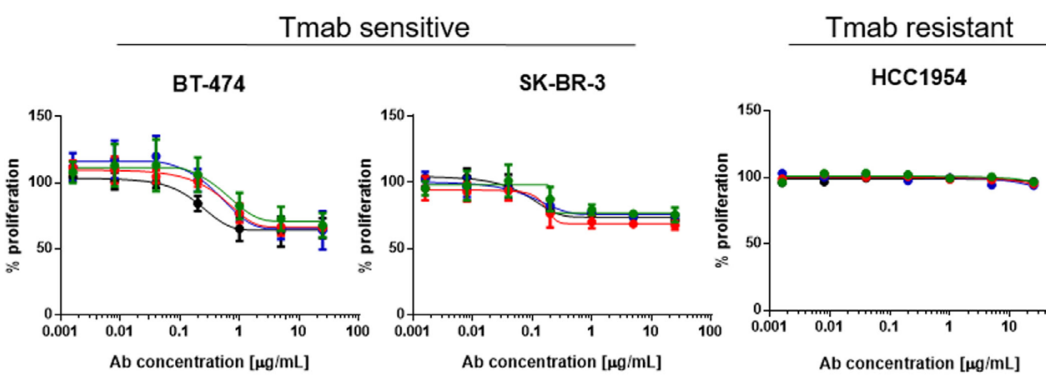

Triple-negative

MDA-MB-231
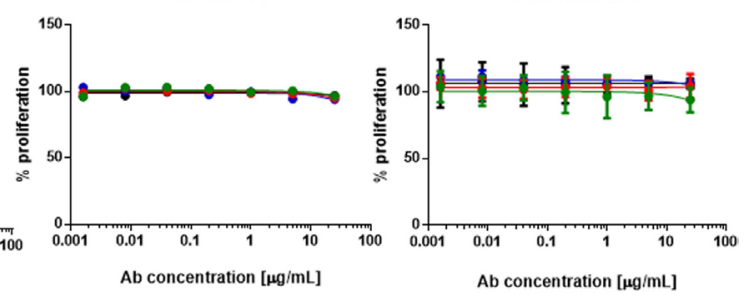

B

Antibody Fc-mediated effects
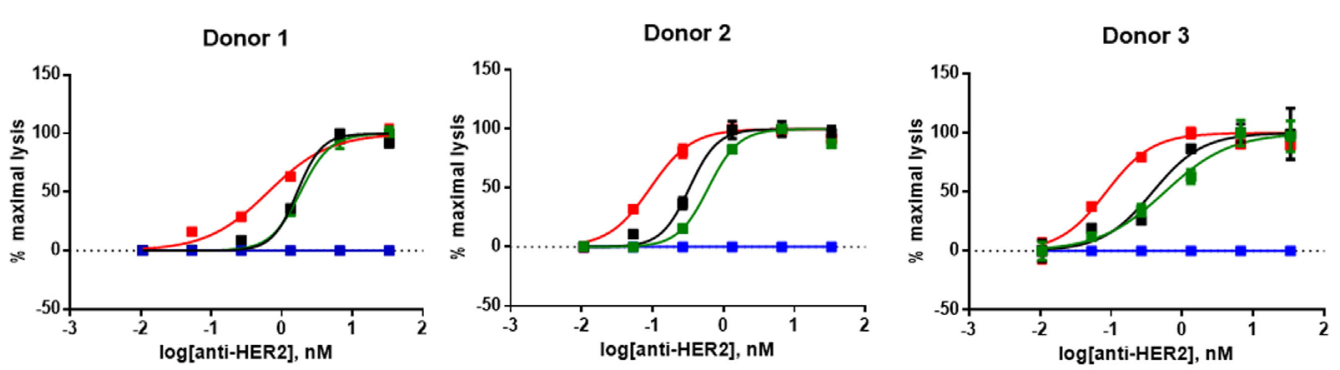

C

\begin{tabular}{|l|c|c|c|}
\hline \multirow{2}{*}{ Ab variant } & \multicolumn{3}{|c|}{ EC50 [nM] } \\
\cline { 2 - 4 } & Donor 1 & Donor 2 & Donor 3 \\
\hline Trastuzumab (Herceptin®) & 1.655 & 0.3307 & 0.3828 \\
\hline Anti-HER2 WT & 1.835 & 0.6106 & 0.5679 \\
\hline Anti-HER2 DE & 0.633 & 0.09277 & 0.08523 \\
\hline Anti-HER2 NQ & N/D & N/D & N/D \\
\hline
\end{tabular}

WT antibody

DE Fc mutant

- NQ Fc mutant

- Trastuzumab (Herceptin®, Roche)

Antibody Fc-mediated effects - HER2 low vs. HER2 high
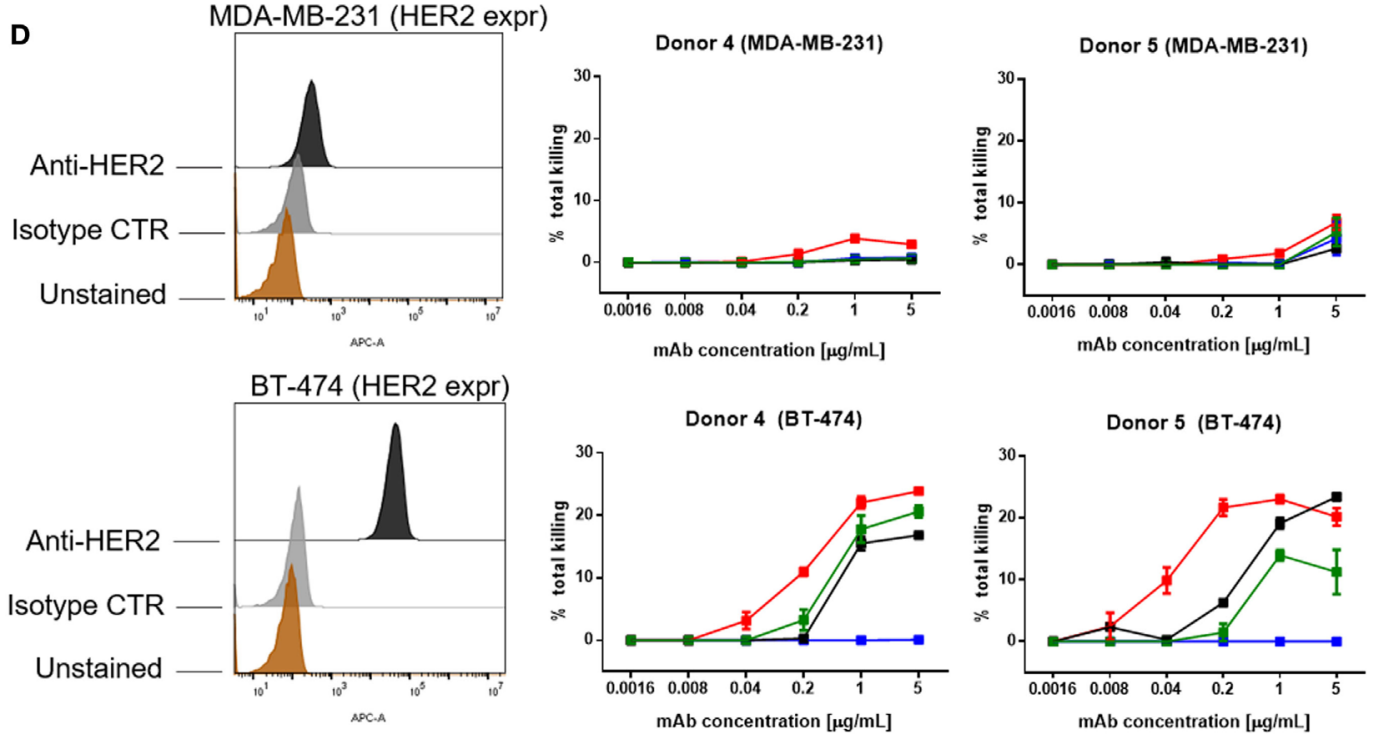

FIGURE 7 | Continued 


\section{FIGURE 7 | Continued}

Assessments of direct and Fc-mediated effects of anti-HER2 Fc variants against breast cancer cells. (A) Effects of anti-HER2 antibody variants on the proliferation of trastuzumab-sensitive (BT-474, SK-BR-3), trastuzumab-resistant (HCC1954) and triple-negative (MDA-MB-231) breast cancer cell lines. Anti-HER2 variants inhibited the proliferation of BT-474 and SK-BR-3 cells in a similar dose-dependent manner, but did not affect the proliferation of MDA-MB-231 or HCC1954 cells. Graphs represent an average of two experiments \pm SD. (B) Human peripheral blood NK cell-mediated ADCC of BT-474 cancer cells induced by anti-HER2 variants measured by LDH release. Graphs are representative of independent experiments with three different human NK cell donors; data were normalized to minimal and maximal cell lysis. Error bars represent SEM values from technical replicates. N/D: not detected. (C) Effective concentration [(EC50) nM] measurements of ADCC by three human NK cell donors. (D) NK cell-mediated ADCC (measured by LDH release) of HER2 low (MDA-MB-231) and HER2 high (BT-474) breast cancer cells induced by anti-HER2 variants. The flow cytometric histograms on the left depict HER2 expression levels in MDA-MB-231 (top) and BT-474 (bottom) compared to unstained cells or cells stained with isotype control mAb. The graphs represent total cell killing levels of MDA-MB-231 cells (top) and BT-474 cells (bottom) mediated by NK cells from two different donors (Donors 4 and 5) at different concentrations of anti-HER2 variants.

picture close to the physiological conditions, where WT therapeutic antibodies would have to compete with endogenous IgGs with similar affinities for their cognate Fc $\gamma$ receptors. This may be addressed through increasing the affinity of therapeutic antibodies to CD16 (59).

We demonstrated that while all anti-HER2 antibody variants retain their Fab-mediated direct effects in restricting HER2expressing breast cancer cell proliferation, Fc-modified anti-HER2 antibodies engender differential anti-tumor cell cytotoxicity potencies by human NK cell effectors. Fc engineering may, therefore, provide a means of manipulating antibody binding kinetics to effector cells, and can alter the antibody's functional capacity and potency to mediate immune effector cell activation and cellmediated cytotoxicity.

Even though there are conflicting reports about the ability of trastuzumab to trigger NK cell-mediated killing in low HER2-expressing cancer cells, in this study, we observed very low ADCC activity of anti-HER2 variants against cancer cells expressing low levels of the target antigen $(51,60)$. Although this may indicate the likely inability of Fc engineered antibodies to target low tumor antigen-expressing cancer cells, these findings could also be interpreted as favorable in terms of potential safety of clinical application of Fc-optimized anti-HER2 antibodies. By targeting high-expressing tumor cells but not low HER2expressing normal tissues, such as cardiomyocytes, their application may engender anti-tumor effects in the absence of on-target, off-tumor toxicities (61).

We confirmed that our generated N297Q mutants completely lack fucosylation. The N297Q mutation most likely results in loss of the core glycan, previously reported to alter the "open" conformation of WT IgG1 antibodies in favor of a "closed" confirmation, leading to impaired ability to engage FcRs (26). On the other hand, loss of fucose from the N-linked core glycan can substantially improve IgG binding to Fcy RIIIA and ADCC. Therefore, differences in the glycosylation of optimized Fc mutants may contribute to their ability to outperform their WT counterparts in FcR engagement and effector cell activation (62). In this study, we demonstrate that the enhanced FcR and Fc-mediated functional attributes of the S293D/I332E mutants are not linked to differential fucosylation. The exact mechanisms behind this functional superiority are currently unknown; unraveling these would require further in-depth structural, interaction, and functional studies.

The importance of engineering monoclonal antibodies with defined Fc functions is highlighted by findings of reduced clinical responses to monoclonal antibodies, such as cetuximab
(anti-EGFR), trastuzumab (anti-HER2), and rituximab (antiCD20), in individuals who carry FCR polymorphisms that alter antibody binding affinities to immune effector cells (63-67). Different approaches have been developed to enhance the potency of monoclonal antibodies in activating effector cells against cancer (21). Optimization of IgG Fc domains through introduction of point mutations or glyco-engineering can influence binding kinetics to FcR. Fc mutant versions of trastuzumab (anti-HER2), alemtuzumab (anti-CD52), rituximab (anti-CD20), and others have shown significantly improved binding to Fc $\gamma$ Rs and enhanced effector functions $(58,68)$. Since removal of fucose from the $N$-linked core glycan can dramatically improve IgG-Fc $\gamma$ RIIIA interactions and ADCC of tumor cells (62), two afucosylated antibodies (obinutuzumab and mogamulizumab) are approved for clinical use in hematological oncology $(69,70)$. An important reported advantage of certain Fc-optimized therapeutic antibodies is that they exhibit enhanced binding to FcyRIIIA even in the presence of polymorphisms that otherwise lower affinity for $\operatorname{IgG}(58,64)$. In this aspect, a future development of our platform could include functional studies of the capacity of Fc-optimized variants to activate NK cells with defined Fc $\gamma$ RIIIA genotype. Specific Fc mutations can also improve antibody pharmacokinetic characteristics through improved binding to the neonatal FcR, FcRn (21). Experimental approaches also entail switching the antibody isotype from the traditionally preferred IgG (mainly IgG1) to other isotypes, such as IgA or IgE, which could also provide advantages through alternative immune surveillance properties in specific tissues and through activating immune effector cell types that may be different to those engaged by $\operatorname{IgG}(18,45,71-74)$.

In this study, we also generated IgG1 antibody variants with vastly reduced FcR engagement and with impaired effector functions. Abrogation of antibody binding to FcRs and abolition of Fc-mediated effector functions is a useful approach for the design of antibodies with direct agonistic or antagonistic activities, antibody-drug conjugates or checkpoint blockade inhibitor antibodies. In some cases, effector cell engagement may not always be desirable, may impede Fab-mediated effects or bear safety hazards if intact Fc-mediated effector functions are retained $(22,23,25,75)$. Antibodies of the IgG2 or IgG4 isotypes are traditional choices in such drug design strategies. Nevertheless, IgG2 and IgG4 antibodies may not completely lack effector cell engagement (76). Furthermore, the latter may retain the potential to interact with other IgG Fc domains or undergo Fab arm exchange (FAE) which can lead to reduced activity or off-target effects (24). Efforts have, therefore, focused toward abolishing Fc-mediated functions 
to avoid potentially dangerous immune-mediated toxicities. In addition, monoclonal antibodies used for cancer therapy are often associated with a range of adverse reactions including triggering cytokine storm or hypersensitivity responses $(22,23)$. Where the purpose of the therapy is to engender Fab-mediated functions (25), complete abrogation of Fc effector capabilities could often be a necessity for certain antibody therapeutic design applications.

Monoclonal antibodies of the same immunoglobulin isotype recognizing different cancer antigens often act through different immune-mediated mechanisms. The same Fc-modifications may engender different effector properties by antibodies with variable specificities and affinities to different antigens or antigenic epitopes. In this context, our approach provides a convenient tool to enable investigation of the effects of Fc point mutations on the function of monoclonal antibodies of any specificity. To exemplify this, we quickly generated Fc variants of monoclonal antibodies against two tumor-associated antigens, with which we were able to delineate antibody Fab-mediated and Fc-mediated mechanisms of action. This demonstrated the capability of the system to enable control of effector functions through introduction of point mutation capabilities. The universal nature of the Fc modification features built into our approach opens the door toward the generation of a range of Fc variants of antibodies of any specificity. Furthermore, serum-free production and quick high antibody yields could provide sufficient high quality material to facilitate early in vitro and in vivo screening, downstream translation to good manufacturing practice (GMP) pathways and facilitate potential clinical application.

In summary, with this design strategy, we are able to manipulate anti-cancer antibody $\mathrm{Fc}$ regions. We delineate the binding and functional attributes of WT and Fc-modified agents and evaluate their Fab-mediated and Fc-mediated functions and potency. This approach can find broad application in therapeutic antibody engineering and translation for cancer therapy and potentially in other areas beyond the cancer immunotherapy field.

\section{ETHICS STATEMENT}

Blood cone samples from anonymized donors were purchased from the National Health Service Blood and Transplant Service, United Kingdom. Sample processing was supported through a local ethical framework conducted in accordance with the Helsinki Declaration and approved by the NHS Research Ethics Committee (Van Cutsem et al.), Guy's and St. Thomas' NHS Trust

\section{REFERENCES}

1. Cuello M, Ettenberg SA, Clark AS, Keane MM, Posner RH, Nau MM, et al. Down-regulation of the erbB-2 receptor by trastuzumab (herceptin) enhances tumor necrosis factor-related apoptosis-inducing ligand-mediated apoptosis in breast and ovarian cancer cell lines that overexpress erbB-2. Cancer Res (2001) 61:4892-900.

2. Fu W, Wang Y, Zhang Y, Xiong L, Takeda H, Ding L, et al. Insights into HER2 signaling from step-by-step optimization of anti-HER2 antibodies. MAbs (2014) 6:978-90. doi:10.4161/mabs.28786

3. Mitri Z, Constantine T, O'Regan R. The HER2 receptor in breast cancer: pathophysiology, clinical use, and new advances in therapy. Chemother Res Pract (2012) 2012:743193. doi:10.1155/2012/743193
("Immunopathogenesis and Molecular Biology in Breast Cancer Subtypes," REC reference number: 13-LO-1248).

\section{AUTHOR CONTRIBUTIONS}

KI, SK, and AT conceived and designed the study. KI, JF-S, TD, SM, SC, PK, and IC helped with the development of the methodology. KI, JF-S, DA, TD, SM, SC, HB, AC, PK, and IC acquired the data or helped with the data analysis and interpretation. KI, JF-S, DA, SM, SC, HB, PK, MF, RM, DJ, AB, JM, JS, EJ-J, AT, and SK discussed and interpreted the data and edited the manuscript. SK and AT supervised the study. SK led and coordinated the project. KI and SK wrote the manuscript.

\section{ACKNOWLEDGMENTS}

We acknowledge the Biomedical Research Centre Immune Monitoring Core Facility team at Guy's and St. Thomas' NHS Foundation Trust for assistance.

\section{FUNDING}

The authors acknowledge support by Breast Cancer Now (147), working in partnership with Walk the Walk; Cancer Research UK (C30122/A11527; C30122/A15774); The European Academy of Allergy and Clinical Immunology; the Medical Research Council (MR/L023091/1); The Academy of Medical Sciences; CR UK/ NIHR in England/DoH for Scotland, Wales and Northern Ireland Experimental Cancer Medicine Centre (C10355/A15587), Austrian Science Fund (FWF) (P23398-B11; W1205-B09). JF-S is a recipient of an EAACI (European Academy of Allergy and Clinical Immunology) Exchange Research Fellowship 2016 and a Boehringer Ingelheim Fonds Travel Grant 2017. The research was supported by the National Institute for Health Research (NIHR) BRC based at Guy's and St. Thomas' NHS Foundation Trust and King's College London (IS-BRC-1215-20006). The views expressed are those of the author(s) and not necessarily those of the NHS, the NIHR, or the Department of Health.

\section{SUPPLEMENTARY MATERIAL}

The Supplementary Material for this article can be found online at http://journal.frontiersin.org/article/10.3389/fimmu.2017.01112/ full\#supplementary-material.

4. Molina MA, Codony-Servat J, Albanell J, Rojo F, Arribas J, Baselga J. Trastuzumab (herceptin), a humanized anti-Her2 receptor monoclonal antibody, inhibits basal and activated Her2 ectodomain cleavage in breast cancer cells. Cancer Res (2001) 61:4744-9.

5. Van Cutsem E, Kohne CH, Hitre E, Zaluski J, Chang Chien CR, Makhson A, et al. Cetuximab and chemotherapy as initial treatment for metastatic colorectal cancer. N Engl J Med (2009) 360:1408-17. doi:10.1056/NEJMoa0805019

6. Weiner GJ. Rituximab: mechanism of action. Semin Hematol (2010) 47:115-23. doi:10.1053/j.seminhematol.2010.01.011

7. Lipson EJ, Drake CG. Ipilimumab: an anti-CTLA-4 antibody for metastatic melanoma. Clin Cancer Res (2011) 17:6958-62. doi:10.1158/1078-0432.ccr-11-1595

8. Postow MA, Callahan MK, Wolchok JD. Immune checkpoint blockade in cancer therapy. J Clin Oncol (2015) 33:1974-82. doi:10.1200/jco.2014.59.4358 
9. Baig NA, Taylor RP, Lindorfer MA, Church AK, Laplant BR, Pavey ES, et al. Complement dependent cytotoxicity in chronic lymphocytic leukemia: ofatumumab enhances alemtuzumab complement dependent cytotoxicity and reveals cells resistant to activated complement. Leuk Lymphoma (2012) 53:2218-27. doi:10.3109/10428194.2012.681657

10. Tohyama Y, Yamamura H. Complement-mediated phagocytosis - the role of Syk. IUBMB Life (2006) 58:304-8. doi:10.1080/15216540600746377

11. Barok M, Isola J, Palyi-Krekk Z, Nagy P, Juhasz I, Vereb G, et al. Trastuzumab causes antibody-dependent cellular cytotoxicity-mediated growth inhibition of submacroscopic JIMT-1 breast cancer xenografts despite intrinsic drug resistance. Mol Cancer Ther (2007) 6:2065-72. doi:10.1158/1535-7163. mct-06-0766

12. Miura D, Yoneyama K, Furuhata Y, Shimizu K. Paclitaxel enhances antibody-dependent cell-mediated cytotoxicity of trastuzumab by rapid recruitment of natural killer cells in HER2-positive breast cancer. J Nippon Med Sch (2014) 81:211-20. doi:10.1272/jnms.81.211

13. Shi Y, Fan X, Deng H, Brezski RJ, Rycyzyn M, Jordan RE, et al. Trastuzumab triggers phagocytic killing of high HER2 cancer cells in vitro and in vivo by interaction with Fcgamma receptors on macrophages. J Immunol (2015) 194:4379-86. doi:10.4049/jimmunol.1402891

14. Valabrega G, Montemurro F, Aglietta M. Trastuzumab: mechanism of action, resistance and future perspectives in HER2-overexpressing breast cancer. Ann Oncol (2007) 18:977-84. doi:10.1093/annonc/mdl475

15. Sockolosky JT, Szoka FC. The neonatal Fc receptor, FcRn, as a target for drug delivery and therapy. Adv Drug Deliv Rev (2015) 91:109-24. doi:10.1016/j. addr.2015.02.005

16. Nimmerjahn F, Ravetch JV. Antibodies, Fc receptors and cancer. Curr Opin Immunol (2007) 19:239-45. doi:10.1016/j.coi.2007.01.005

17. Chames P, Van Regenmortel M, Weiss E, Baty D. Therapeutic antibodies: successes, limitations and hopes for the future. Br JPharmacol (2009) 157:220-33. doi:10.1111/j.1476-5381.2009.00190.x

18. Josephs DH, Spicer JF, Karagiannis P, Gould HJ, Karagiannis SN. IgE immunotherapy: a novel concept with promise for the treatment of cancer. MAbs (2014) 6:54-72. doi:10.4161/mabs.27029

19. Beers SA, Glennie MJ, White AL. Influence of immunoglobulin isotype on therapeutic antibody function. Blood (2016) 127:1097-101. doi:10.1182/ blood-2015-09-625343

20. White AL, Chan HT, Roghanian A, French RR, Mockridge CI, Tutt AL, et al. Interaction with FcgammaRIIB is critical for the agonistic activity of anti-CD40 monoclonal antibody. J Immunol (2011) 187:1754-63. doi:10.4049/ jimmunol.1101135

21. Park HI, Yoon HW, Jung ST. The highly evolvable antibody Fc domain. Trends Biotechnol (2016) 34:895-908. doi:10.1016/j.tibtech.2016.04.005

22. Baldo BA. Adverse events to monoclonal antibodies used for cancer therapy: focus on hypersensitivity responses. Oncoimmunology (2013) 2:e26333. doi:10.4161/onci.26333

23. Brennan FR, Morton LD, Spindeldreher S, Kiessling A, Allenspach R, Hey A, et al. Safety and immunotoxicity assessment of immunomodulatory monoclonal antibodies. MAbs (2010) 2:233-55. doi:10.4161/mabs.2.3.11782

24. Crescioli S, Correa I, Karagiannis P, Davies AM, Sutton BJ, Nestle FO, et al. IgG4 characteristics and functions in cancer immunity. Curr Allergy Asthma Rep (2016) 16:7. doi:10.1007/s11882-015-0580-7

25. Jacobsen FW, Stevenson R, Li C, Salimi-Moosavi H, Liu L, Wen J, et al. Engineering an IgG scaffold lacking effector function with optimized developability. J Biol Chem (2017) 292:1865-75. doi:10.1074/jbc.M116.748525

26. Krapp S, Mimura Y, Jefferis R, Huber R, Sondermann P. Structural analysis of human IgG-Fc glycoforms reveals a correlation between glycosylation and structural integrity. J Mol Biol (2003) 325:979-89. doi:10.1016/ S0022-2836(02)01250-0

27. Roghanian A, Teige I, Martensson L, Cox KL, Kovacek M, Ljungars A, et al. Antagonistic human FcgammaRIIB (CD32B) antibodies have anti-tumor activity and overcome resistance to antibody therapy in vivo. Cancer Cell (2015) 27:473-88. doi:10.1016/j.ccell.2015.03.005

28. Sazinsky SL, Ott RG, Silver NW, Tidor B, Ravetch JV, Wittrup KD. Aglycosylated immunoglobulin G1 variants productively engage activating Fc receptors. Proc Natl Acad Sci U S A (2008) 105:20167-72. doi:10.1073/ pnas.0809257105

29. Bebbington CR, Renner G, Thomson S, King D, Abrams D, Yarranton GT. High-level expression of a recombinant antibody from myeloma cells using a glutamine synthetase gene as an amplifiable selectable marker. Nat Biotechnol (1992) 10:169-75.

30. Maynard J, Georgiou G. Antibody engineering. Annu Rev Biomed Eng (2000) 2:339-76. doi:10.1146/annurev.bioeng.2.1.339

31. Zafir-Lavie I, Michaeli Y, Reiter Y. Novel antibodies as anticancer agents. Oncogene (2007) 26:3714-33. doi:10.1038/sj.onc.1210372

32. Tanaka T, Yamada H, Kuroki M, Kodama S, Tamura K, Takamatsu Y. A modified adenovirus vector-mediated antibody screening method identifies EphA2 as a cancer target. Transl Oncol (2017) 10:476-84. doi:10.1016/j. tranon.2017.04.001

33. Yu X, Wang L, Shen Y, Wang C, Zhang Y, Meng Y, et al. Targeting EGFR/ HER2 heterodimerization with a novel anti-HER2 domain II/III antibody. Mol Immunol (2017) 87:300-7. doi:10.1016/j.molimm.2017.05.010

34. Saeed AF, Wang R, Ling S, Wang S. Antibody engineering for pursuing a healthier future. Front Microbiol (2017) 8:473-88. doi:10.3389/fmicb.2017.00495

35. Li F, Vijayasankaran N, Shen AY, Kiss R, Amanullah A. Cell culture processes for monoclonal antibody production. MAbs (2010) 2:466-79. doi:10.4161/ mabs.2.5.12720

36. Dodev TS, Karagiannis P, Gilbert AE, Josephs DH, Bowen H, James LK, et al. A tool kit for rapid cloning and expression of recombinant antibodies. Sci Rep (2014) 4:5885. doi:10.1038/srep05885

37. Klock HE, Koesema EJ, Knuth MW, Lesley SA. Combining the polymerase incomplete primer extension method for cloning and mutagenesis with microscreening to accelerate structural genomics efforts. Proteins (2008) 71:982-94. doi:10.1002/prot.21786

38. Ho SN, Hunt HD, Horton RM, Pullen JK, Pease LR. Site-directed mutagenesis by overlap extension using the polymerase chain reaction. Gene (1989) 77:51-9. doi:10.1016/0378-1119(89)90358-2

39. Reikofski J, Tao BY. Polymerase chain reaction (PCR) techniques for site-directed mutagenesis. Biotechnol Adv (1992) 10:535-47. doi:10.1016/ 0734-9750(92)91451-J

40. Unger T, Jacobovitch Y, Dantes A, Bernheim R, Peleg Y. Applications of the restriction free (RF) cloning procedure for molecular manipulations and protein expression. J Struct Biol (2010) 172:34-44. doi:10.1016/j.jsb.2010.06.016

41. Wang X, Osada T, Wang Y, Yu L, Sakakura K, Katayama A, et al. CSPG4 protein as a new target for the antibody-based immunotherapy of triplenegative breast cancer. J Natl Cancer Inst (2010) 102:1496-512. doi:10.1093/ jnci/djq343

42. Gauld SB, Benschop RJ, Merrell KT, Cambier JC. Maintenance of B cell anergy requires constant antigen receptor occupancy and signaling. Nat Immunol (2005) 6:1160-7. doi:10.1038/ni1256

43. Beard RE, Zheng Z, Lagisetty KH, Burns WR, Tran E, Hewitt SM, et al. Multiple chimeric antigen receptors successfully target chondroitin sulfate proteoglycan 4 in several different cancer histologies and cancer stem cells. J Immunother Cancer (2014) 2:25. doi:10.1186/2051-1426-2-25

44. Price MA, Colvin Wanshura LE, Yang J, Carlson J, Xiang B, Li G, et al. CSPG4, a potential therapeutic target, facilitates malignant progression of melanoma. Pigment Cell Melanoma Res (2011) 24:1148-57. doi:10.1111/j.1755-148X. 2011.00929.x

45. Karagiannis P, Singer J, Hunt J, Gan SK, Rudman SM, Mechtcheriakova D, et al. Characterisation of an engineered trastuzumab IgE antibody and effector cell mechanisms targeting HER2/neu-positive tumour cells. Cancer Immunol Immunother (2009) 58:915-30. doi:10.1007/s00262-008-0607-1

46. Neri D, Natali PG, Petrul H, Soldani P, Nicotra MR, Vola R, et al. Recombinant anti-human melanoma antibodies are versatile molecules. J Invest Dermatol (1996) 107:164-70. doi:10.1111/1523-1747.ep12329566

47. Nimmerjahn F, Ravetch JV. Fcgamma receptors as regulators of immune responses. Nat Rev Immunol (2008) 8:34-47. doi:10.1038/nri2206

48. Karamouzis MV, Konstantinopoulos PA, Papavassiliou AG. Trastuzumab mechanism of action and use. N Engl J Med (2007) 357:1664; author reply 1665-6. doi:10.1056/NEJMc072213

49. O'Brien NA, Browne BC, Chow L, Wang Y, Ginther C, Arboleda J, et al. Activated phosphoinositide 3-kinase/AKT signaling confers resistance to trastuzumab but not lapatinib. Mol Cancer Ther (2010) 9:1489-502. doi:10.1158/1535-7163.mct-09-1171

50. Braren I, Greunke K, Pilette C, Mempel M, Grunwald T, Bredehorst R, et al. Quantitation of serum IgE by using chimeras of human IgE receptor and avian immunoglobulin domains. Anal Biochem (2011) 412:134-40. doi:10.1016/j. ab.2010.12.013 
51. Barok M, Tanner M, Koninki K, Isola J. Trastuzumab-DM1 causes tumour growth inhibition by mitotic catastrophe in trastuzumab-resistant breast cancer cells in vivo. Breast Cancer Res (2011) 13:R46. doi:10.1186/bcr2868

52. Borrok MJ, Luheshi NM, Beyaz N, Davies GC, Legg JW, Wu H, et al. Enhancement of antibody-dependent cell-mediated cytotoxicity by endowing IgG with FcalphaRI (CD89) binding. MAbs (2015) 7:743-51. doi:10.1080/ 19420862.2015.1047570

53. Zhang F, Zhang J, Liu M, Zhao L, LingHu R, Feng F, et al. Combating HER2overexpressing breast cancer through induction of calreticulin exposure by Tras-Permut CrossMab. Oncoimmunology (2015) 4:e994391. doi:10.4161/ 2162402x.2014.994391

54. Galluzzi L, Vacchelli E, Bravo-San Pedro JM, Buque A, Senovilla L, Baracco EE, et al. Classification of current anticancer immunotherapies. Oncotarget (2014) 5:12472-508. doi:10.18632/oncotarget.2998

55. Scott AM, Allison JP, Wolchok JD. Monoclonal antibodies in cancer therapy. Cancer immun (2012) 12:14.

56. Scott AM, Wolchok JD, Old LJ. Antibody therapy of cancer. Nat Rev Cancer (2012) 12:14. doi:10.1038/nrc3236

57. Gibson DG, Young L, Chuang RY, Venter JC, Hutchison CA III, Smith HO. Enzymatic assembly of DNA molecules up to several hundred kilobases. Nat Methods (2009) 6:343-5. doi:10.1038/nmeth.1318

58. Lazar GA, Dang W, Karki S, Vafa O, Peng JS, Hyun L, et al. Engineered antibody Fc variants with enhanced effector function. Proc Natl Acad Sci U S A (2006) 103:4005-10. doi:10.1073/pnas.0508123103

59. Nechansky A, Schuster M, Jost W, Siegl P, Wiederkum S, Gorr G, et al. Compensation of endogenous IgG mediated inhibition of antibodydependent cellular cytotoxicity by glyco-engineering of therapeutic antibodies. Mol Immunol (2007) 44:1815-7. doi:10.1016/j.molimm.2006.08.013

60. Collins DM, O'Donovan N, McGowan PM, O'Sullivan F, Duffy MJ, Crown J. Trastuzumab induces antibody-dependent cell-mediated cytotoxicity (ADCC) in HER-2-non-amplified breast cancer cell lines. Ann Oncol (2012) 23:1788-95. doi:10.1093/annonc/mdr484

61. Press MF, Cordon-Cardo C, Slamon DJ. Expression of the HER-2/neu proto-oncogene in normal human adult and fetal tissues. Oncogene (1990) 5:953-62.

62. Niwa R, Satoh M. The current status and prospects of antibody engineering for therapeutic use: focus on glycoengineering technology. J Pharm Sci (2015) 104:930-41. doi:10.1002/jps.24316

63. Liu D, Tian Y, Sun D, Sun H, Jin Y, Dong M. The FCGR3A polymorphism predicts the response to rituximab-based therapy in patients with non-Hodgkin lymphoma: a meta-analysis. Ann Hematol (2016) 95:1483-90. doi:10.1007/ s00277-016-2723-x

64. Mellor JD, Brown MP, Irving HR, Zalcberg JR, Dobrovic A. A critical review of the role of Fc gamma receptor polymorphisms in the response to monoclonal antibodies in cancer. J Hematol Oncol (2013) 6:1. doi:10.1186/ 1756-8722-6-1

65. Musolino A, Naldi N, Bortesi B, Pezzuolo D, Capelletti M, Missale G, et al. Immunoglobulin $\mathrm{G}$ fragment $\mathrm{C}$ receptor polymorphisms and clinical efficacy of trastuzumab-based therapy in patients with HER-2/neu-positive metastatic breast cancer. J Clin Oncol (2008) 26:1789-96. doi:10.1200/jco.2007.14.8957
66. Pandey JP, Namboodiri AM. Genetic variants of IgG1 antibodies and FcgammaRIIIa receptors influence the magnitude of antibody-dependent cell-mediated cytotoxicity against prostate cancer cells. Oncoimmunology (2014) 3:e27317. doi:10.4161/onci.27317

67. Tamura K, Shimizu C, Hojo T, Akashi-Tanaka S, Kinoshita T, Yonemori K, et al. FcgammaR2A and 3A polymorphisms predict clinical outcome of trastuzumab in both neoadjuvant and metastatic settings in patients with HER2-positive breast cancer. Ann Oncol (2011) 22:1302-7. doi:10.1093/ annonc/mdq585

68. Richards JO, Karki S, Lazar GA, Chen H, Dang W, Desjarlais JR. Optimization of antibody binding to FcgammaRIIa enhances macrophage phagocytosis of tumor cells. Mol Cancer Ther (2008) 7:2517-27. doi:10.1158/1535-7163. mct-08-0201

69. Beck A, Reichert JM. Marketing approval of mogamulizumab: a triumph for glyco-engineering. MAbs (2012) 4:419-25. doi:10.4161/mabs.20996

70. Jean GW, Comeau JM. Role of obinutuzumab in the treatment of chronic lymphocytic leukemia. Am J Health Syst Pharm (2015) 72:933-42. doi:10.2146/ ajhp 140282

71. Dechant M, Valerius T. IgA antibodies for cancer therapy. Crit Rev Oncol Hematol (2001) 39:69-77. doi:10.1016/S1040-8428(01)00105-6

72. Josephs DH, Bax HJ, Dodev T, Georgouli M, Nakamura M, Pellizzari G, et al. Anti-folate receptor-alpha $\operatorname{IgE}$ but not $\mathrm{IgG}$ recruits macrophages to attack tumors via TNFalpha/MCP-1 signaling. Cancer Res (2017) 77:1127-41. doi:10.1158/0008-5472.can-16-1829

73. Karagiannis SN, Josephs DH, Bax HJ, Spicer JF. Therapeutic IgE antibodies: harnessing a macrophage-mediated immune surveillance mechanism against cancer. Cancer Res (2017) 77:2779-83. doi:10.1158/0008-5472.can-17-0428

74. Karagiannis SN, Wang Q, East N, Burke F, Riffard S, Bracher MG, et al. Activity of human monocytes in IgE antibody-dependent surveillance and killing of ovarian tumor cells. Eur J Immunol (2003) 33:1030-40. doi:10.1002/ eji.200323185

75. Arlauckas SP, Garris CS, Kohler RH, Kitaoka M, Cuccarese MF, Yang KS, et al. In vivo imaging reveals a tumor-associated macrophage-mediated resistance pathway in anti-PD-1 therapy. Sci Transl Med (2017) 9:eaal3604. doi:10.1126/ scitranslmed.aal3604

76. Karagiannis P, Gilbert AE, Josephs DH, Ali N, Dodev T, Saul L, et al. IgG4 subclass antibodies impair antitumor immunity in melanoma. J Clin Invest (2013) 123:1457-74. doi:10.1172/jci65579

Conflict of Interest Statement: SK and JS are founders and shareholders of IGEM Therapeutics Ltd. All other authors declare not conflicts of interest.

Copyright (c) 2017 Ilieva, Fazekas-Singer, Achkova, Dodev, Mele, Crescioli, Bax, Cheung, Karagiannis, Correa, Figini, Marlow, Josephs, Beavil, Maher, Spicer, JensenJarolim, Tutt and Karagiannis. This is an open-access article distributed under the terms of the Creative Commons Attribution License (CC BY). The use, distribution or reproduction in other forums is permitted, provided the original author(s) or licensor are credited and that the original publication in this journal is cited, in accordance with accepted academic practice. No use, distribution or reproduction is permitted which does not comply with these terms. 